\title{
Das Mikrobiom - die unplanbare Größe zukünftiger Therapien
}

\section{The Microbiome - The Unscheduled Parameter for Future Therapies}

(c) (1)

Autor

Achim G. Beule1, 2

Institute

1 HNO-Uniklinik Münster

2 Klinik und Poliklinik für Hals-Nasen-Ohrenkrankheiten der Universitätsmedizin Greifswald

Schlüsselwörter

Mikrobiom, Sinusitis, Kopf-Hals-Tumoren, Otitis

Key words

Microbiome, sinusitis, head and neck cancer, otitis

Bibliografie

DOI https://doi.org/10.1055/s-0043-122301

Laryngo-Rhino-Otol 2018; 97: S279-S295

(c) Georg Thieme Verlag KG Stuttgart · New York ISSN 0935-8943

Korrespondenzadresse

Priv.-Doz. Dr. med. habil. Achim Georg Beule

HNO-Uniklinik Münster

Kardinal von Galen Ring 10

D-48149 Münster

AchimGeorg.Beule@ukmuenster.de

\section{ZUSAMMENFASSUNG}

Unter Mikrobiom versteht man die Gesamtheit der bakteriellen, parasitären, viralen oder anderen zellulären Mikroorganismen, die den menschlichen Körper oder ein anderes Lebewesen besiedeln. Das Mikrobiom zeigt in den anatomischen Bereichen der Hals-Nasen-Ohrenheilkunde eine deutliche regionale Varianz. Für die Bereiche von Ohr, Nase, Rachen, Larynx und Haut sind jeweils verschiedene Interaktionen des Mikrobiomes mit allgemeinen Faktoren wie Alter, Diät und Lebensstilfaktoren (z. B. Rauchen) in den letzten Jahren bekannt geworden. Zudem liegen eine Reihe von Erkenntnissen vor, dass das Mikrobiom an der Pathogenese verschiedener Erkrankungen auch im HNO-Bereich beteiligt ist. Der vorgestellte Übersichtsartikel fasst die wesentlichen Erkenntnisse dieses sich aktuell äußerst rasch entwickelnden Forschungsgebietes überblickartig zusammen.

\section{ABSTRACT}

The microbiome is defined as the total of cellular microorganisms of baczerial, viral or e. g., parasite origin living on the surface of a body. Within the anatomical areas of otorhinolaryngology, a significant divergence and variance can be demonstrated. For ear, nose, throat, larynx and cutis different interactions of microbiome and common factors like age, diet and live style factors (e. g., smoking) have been detected in recent years. Besides, new insights hint at a passible pathognomic role of the microbiome towards diseases in the ENT area. This review article resumes the present findings of this rapidly devloping scientific area.
Inhaltsverzeichnis

Zusammenfassung

Abstract

1. Einleitung und Definition

2. Terminologie

2.1 Taxonomie der Bakterien

3. Einflussfaktoren auf das Mikrobiom allgemein

3.1 Ablauf einer Mikrobiom-Studie

3.2 Entnahmetechniken und technische Aspekte

3.3 Allgemeine Einflussfaktoren

3.1.1 Alter
3.3.2 Gender

3.3.3 Rauchen

3.4 Ernährung

3.5 Antibiotikatherapie $\$ 285$

$\begin{array}{lll}3.6 & \text { Impfung } & \text { S285 }\end{array}$

4. Mikrobiom in der HNO-Heilkunde $\$ 285$

$\begin{array}{lll}4.1 & \text { Ohr } & \text { S285 }\end{array}$

4.2 Nasenrachen $\quad$ S286

4.3 Nase und Nasennebenhöhlen S286

4.3.1 Allergische Rhinitis $\quad$ S287 
4.3.2 Mikrobiom und chronische Rhinosinusitis

4.4 Mundraum

4.4.1 Mikrobiom des Speichels

4.5 Rachenraum

4.5.1 Exkurs: Mikrobiom und Immunsystem

4.6 Larynx

4.7 Trachea

4.8 Ösophagus

4.8.1 Gastro-ösophagealer Reflux

4.8.2 Neubildungen

5. Kopf-Hals-Tumoren und deren Behandlung

$5.1 \quad$ Karzinogenese

5.2 Mikrobiome und Checkpoint-Inhibitoren

5.3 Ausblick

Literatur

\begin{tabular}{|c|c|}
\hline \multicolumn{2}{|c|}{ ABKÜRZUNGEN } \\
\hline CRS & chronische Rhinosinusitis \\
\hline OUT & operational taxonomic unit \\
\hline \multirow[t]{2}{*}{ MALDI-TOF } & Matrix Assisted Laser Ionization Mass \\
\hline & Spectrometry-Time of Flight \\
\hline Teff & Effektor-T-Zellen \\
\hline Treg & Regulatorische T-Zellen \\
\hline
\end{tabular}

\section{Einleitung und Definition}

Das Mikrobiom bezeichnet im weiteren Sinne die Gesamtheit aller den Menschen oder andere Lebewesen (z. B. Regenwürmer, Reptilien, Rinder) besiedelnden Mikroorganismen. Diese Zusammensetzung der Mikroorganismen unterscheidet sich stark lokal. Sie setzen sich zusammen aus Bakterien (planktonisch und als Biofilme), Viren, Pilzen und allen anderen Arten von Mikroorganismen (Archaea, Amöben, Flagellaten, Bakteriophagen usw.). Lebewesen, bei denen künstlich eine Auseinandersetzung mit dem Mikrobiom verhindert wird, verbleiben physiologisch unreif bei wichtigen Regulationsmechanismen wie der Immunabwehr und sind pathogenen Erregern gegenüber sehr anfällig [1]. Neben systemischen Effekten dieser Art beeinflusst das Mikrobiom die Epithelfunktion des Lebewesens im Bereich aller Körperoberflächen, also auch der HNO-Heilkunde.

Aufgrund der unterschiedlichen lokalen Milieus unterscheidet sich das Mikrobiom auf Haut und Schleimhaut, aber auch in den verschiedenen Regionen des Hals-Nasen-Ohren-Fachbereiches. Ferner ändert sich die Zusammensetzung der Mikroorganismen reaktiv durch Alterung des Wirtsorganismus, Auftreten von Erkrankungen und auch in Abhängigkeit von Therapien. Es mag verschiedene Erkrankungen hervorrufen bzw. deren Entstehung begünstigen. Zu diesen gehört unter anderem das Risiko an bösartigen Erkrankungen zu erkranken.

Das humane Mikrobiom wird durch fortgeschrittene Sequenzierung der DNA festgestellt und umfasst sowohl pathogene -, wie kom- mensale Mikroben. Individuelle Unterschiede werden als Ursache angesehen, die Suszeptibilität zwischen Patienten und ihrem Risiko an Erkrankung zu erkranken, zu erklären. Die Beeinflussung der Suszeptibilität erfolgt über Faktoren, wie die Ernährung, den Stoffwechsel, die Entgiftung, den Hormonstatus, die Immuntoleranz und besonders Entzündungsabläufe [2-5].

Das Mikrobiom des Menschen ist Teil intensiver Forschung und noch nicht umfassend verstanden. Seit Dezember 2007 wird in den USA im Rahmen des Human Microbiome Project (https://hmpdacc. org/), initiiert durch das National Institute of Health, die Sequenzierung aller Genome der Mikroorganismen, die den Menschen besiedeln, als Ziel verfolgt. Der Untersuchung liegen Stichproben aus Mund, Rachen und Nase, der Haut, dem Verdauungstrakt und dem Urogenitaltrakt von Frauen zugrunde. Es wurde eine spezifische Datenbank eingerichtet, um die Zusammenarbeit zwischen den Gruppen zu erleichtern [3].

Seit 2008 wird separat das Mund-Mikrobiom vom National Institute of Dental and Craniofacial Research (NIDCR) detailliert untersucht. Dieses umfasst allein bereits mehr als 600 Mikroorganismen. Parallel werden auch die Mikrobiome anderer definierter Körperregionen untersucht. Vor dem Hintergrund dieser intensiven wissenschaftlichen Untersuchungen haben sich Fachmitteilungen zur Bedeutung des Mikrobioms in den letzten Jahren exponentiell vermehrt. So liegen derzeit mehr als 30000 Publikationen zu diesem Themengebiet, davon insgesamt 400 spezifisch für das Gebiet der HNO-Heilkunde, vor. Obwohl noch viele Aspekte zum Mikrobiom ungeklärt sind, liegen zu allen Subspezialisierungen der HNO-Heilkunde mittlerweile wesentliche grundlegende Erkenntnisse vor.

Die Peer-Reviewed Publikationen entwickeln sich im Bereich „Mikrobiom “ rasant. - Abb. 1 stellt die Anzahl pro Jahr der unter www. pubmed.com gelisteten Publikationen denen gegenüber, die aus dem Bereich der Hals-Nasen-Ohrenheilkunde kommen bzw. für diese besonders relevant sind. Definiert wurde dieser Umstand durch eine Abfrage nach den Stichworten „microbiome AND (rhinology or otology or otitis or nose or sinus or (head and neck) or laryngology)“, die naturgemäß aufgrund der Heterogenität des Fachgebietes keinen Anspruch auf Vollständigkeit haben kann. Dies zeigt schon der Blick auf die für diese Übersichtsarbeit zitierten Arbeiten. \ Abb. 1 zeigt aber mit 274 Publikationen auf rhinologischem, 153 auf laryngologisch/onkologischem und 124 auf otologischem Gebiet eine gleichartige, dynamisch aufsteigenden Entwicklung auch für unser Fachgebiet. Nach eingehendem Literaturstudium ist dabei zum derzeitigen Zeitpunkt sowohl aufgrund der geringen Vergleichbarkeit bei schnell aufeinanderfolgenden, technischen Entwicklungen, wie auch der hohen Anzahl von Einflussfaktoren die praktische Konsequenz dieser Arbeiten für die Klinik stark limitiert, für die Grundlagenforschung und Entwicklung neuartiger Therapieansätze aber höchst interessant.

Bei der Bearbeitung von Fragen zum Mikrobiom sind nach Entwicklung erster technischer Standards eine Reihe von Fragen definiert worden, basierend auf den Erkenntnissen der gegenseitigen, nertzwerk-artigen Beeinflussung von Mikrobiom und Wirt, die - Abb. 2 stichwortig erfasst und auf die im Folgenden dann soweit möglich inhaltlich eingegangen werden soll.

Das Humane Mikrobiom Datenportal, zugänglich unter https:// hmpdacc.org/ weist den aktuellen Forschungsstand des Mikrobiomes inklusiver der auch von gesunden Probanden verfügbaren Daten 


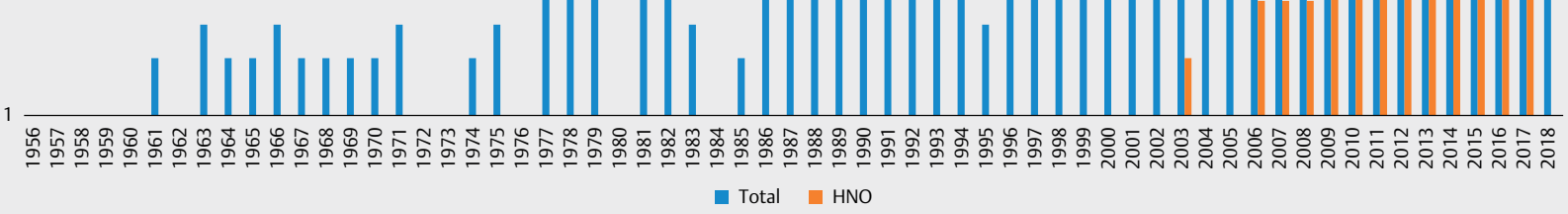

- Abb. 1 Anzahl der von Pubmed aufgeführten Publikationen nach den Suchbegriffen „microbiome“ (Total) bzw. (microbiome AND (rhinology or Otology or otitis or nose or sinus or (Head and Neck) or laryngology), hier als „HNO“ aufgeführt (Stichtag: 01.10.2017).

- Wie beeinflussen sich Mikrobiom und Gesundheitsstatus gegenseitig?

- Welche inter- und intraindividuelle Unterschiede gibt es?

- Wie relevant sind die bislang beobachteten Unterschiede?

- Welchen Einfluss haben Alter, Geschlecht, Lebensweise, Klima, Tageszeit u.a. physiologische Einflussfaktoren?

- Wie stabil ist das Mikrobiom und wie und wie schnell und wie lange reagiert es auf Störungen (Resilienz) wie akute Infektionen?

- Kann man das Mikrobiom therapeutisch nutzen?

- Wie reagiert Mikrobiom und Wirt auf Antibiotikagabe, Immunsuppression oder -therapie?

- Welche internationalen Unterschiede im Mikrobiom sind auf das Gesundheitssystem, (Verschreibungsverhalten), genetische Unterschiede oder die Lebensweise zurückzuführen?

Abb. 2 Offene Frage zur Bedeutung des Mikrobiomes.

auf. Gemäß der aktuell abrufbaren Daten (https://portal.hmpdacc. org/) gehören Mikrobiom-Daten der HNO-Regionen zu den meist verfügbaren Referenzdaten. Im Detail stehen die HNO-ärztlichen Lokalisationen Wangenschleimhaut im Ranking auf Position 2 der meisten Referenzdaten, gefolgt von Gingiva (Position 5), Nasenhaupthöhle (7), Zungenrücken (9), Nares (10), Gaumenmandeln (11), rechter (12) bzw. linker (15) Ohrumschlagfalte, Hartgaumen (13), Rachen (14), Speichel (16), Nasopharynx (23) und Mundhöhle (34). Dabei werden die verfügbaren Referenzdaten jeweils auch unter technischen Gesichtspunkten kategorisiert angeboten.

\begin{tabular}{|l|l|l|}
\hline Taxonomische Rangstufen / Taxa \\
\hline Latein & Deutsch & Englisch \\
\hline Regnum & Reich & Kingdom \\
\hline Phylum & Stamm & Phylum \\
\hline Classis & Klasse & class \\
\hline Ordo & Ordnung & Order \\
\hline Familia & Familie & Family \\
\hline Genus & Gattung & Genus \\
\hline Spezies & Art & Species \\
\hline
\end{tabular}

Abb. 3 Taxonomische Rangstufen im internationalen Sprachgebrauch.

\section{Terminologie}

Zur besseren Verständlichkeit des folgenden Textes, aber auch der internationalen Literatur, werden im Folgenden einige grundlegende Begriffe als Termini technici eingeführt:

Taxon/Taxa ist der Überbegriff für eine/mehrere Gruppen von Lebewesen, die sich anhand gemeinsamer Merkmale von anderen Organismen abgrenzen und unterscheiden lässt. Mit Bezug zum Mikrobiom wird es als Überbegriff zur Rangstufe von Mikroorganismen bezeichnet ( $\mathbf{A} \mathbf{A b}$. $\mathbf{3}$ ):

Veränderungen des Mikrobioms werden üblicherweise als Alphaund Beta-Diversität berichtet. Dabei ist die Alpha-Diversität das Maß der verschiedenen Arten von Mikroorganismen, die in einem Individuum bzw. dessen untersuchter Region nachgewiesen werden können. Die Alpha-Diversität wird auch als „Punktdiversität“ bezeichnet 
und stellt ein Maß für die Artenvielfalt eines Lebensraums dar. Der Ausdruck wurde durch den Ökologen Robert Whittaker 1960 eingeführt.

So besitzt bspw. der Mundraum die höchste Alpha-Diversität des Verdauungstraktes mit über 1000 verschiedenen nachgewiesenen bakteriellen Spezies unter Beteiligung von aeroben und anaeroben Arten.

Als Beta-Diversität wird dagegen die Variabilität zwischen Individuen im gleichen Lebensraum im Hinblick auf die nachgewiesenen Mikroorganismen unterschieden. Auch dieser Begriff geht auf Robert Whittaker zurück und versteht sich als Maß für den Unterschied in der Artenvielfalt.

Die Gamma-Diversität, ein Maß der Artenvielfalt einer Landschaft, beginnend von ca. 1000 ha bis hin zu ca. 1000000 ha, und die Epsilon-Diversität, die die Artenvielfalt mehrerer Landschaften in einer geografischen Region beschreibt, spielen bislang zwar in der biologischen Literatur, nicht aber in der medizinischen Welt eine Rolle.

Die Verbindung zwischen einem veränderten Mikrobiom zu einer spezifischen Erkrankung wird als Dysbiose bezeichnet, was voraussichtlich zurückzuführen ist auf ein Bakterium, das als „Alpha Bug“ eine ökologische Nische ausnutzt [2]. Dysbioseverbundene Entzündungen verursachen genauso wie chemische Karzinogene, wie Acethylaldehyd und N-Nitratverbindungen, eine Karzinogenese über verschiedene Stoffwechselwege.

\subsection{Taxonomie der Bakterien}

Die Klassifikation der Bakterien erfolgt im Rahmen der MikrobiomUntersuchungen basierend auf Aussehen, Physiologie und Phylogenetik. Zur Bezeichnung der Bakterien wurden Namen entsprechend den Anforderungen des 1980 reformierten Internationalen Codes der Nomenklatur von Bakterien (ICNB) definiert. Jede Bezeichnung basiert auf hinterlegtem Typusmaterial, anhand dessen ein Bakterium einem Taxon zugeordnet wird.

Benennt wird ein Mikroorganismus eindeutig anhand seines hinterlegten Typusmaterials als identifizierbares Taxon. Die Bezeichnung und Zuordnung unterliegt wissenschaftlich bedingten Veränderungen. Die aktuellen Taxa sind jeweils aktuell in Bergley's Manual of Systematic Bacteriology [6] publiziert.

\section{Einflussfaktoren auf das Mikrobiom allgemein}

Mittels traditioneller kultureller Anzuchtverfahren können nur ein Bruchteil der Mikroorganismen des Mikrobioms isoliert und charakterisiert werden. Diese wurden daher durch kulturunabhängige DNAbasierte Sequenzierungsmethoden abgelöst.

\subsection{Ablauf einer Mikrobiom-Studie}

Diese Techniken kommen im Rahmen von Mikrobiom-Studien nahezu ausschließlich zum Einsatz. Bei diesen Techniken wird die genetische Information der kleinen Untereinheit der ribosomalen RNA (16 S-rRNA) zur taxonomischen Charakterisierung amplifiziert und sequenziert. Die ribosomalen Nukleinsäuren sind ein Teil der bakteriellen Ribosomen, die aus Geninformationen die passenden Proteine zusammenbauen. Sie werden sequenziert, um Bakterienarten eindeutig zu identifizieren und voneinander zu unterscheiden. Die 16 S-rRNA ist hochkonserviert im Hinblick auf die genetische Information und damit für eine taxonomische Einordnung besonders gut geeignet.

Der prinzipielle Ablauf einer Mikrobiom-Studie sollte stark standardisiert ablaufen ( $\mathbf{A b b} \mathbf{4} \mathbf{4})$ :

Die gesammelten Gewebsproben werden ohne Kontaminationen gefroren und stabilisiert, die DNA extrahiert und mittels $10^{5}$ Sequenzen als rRNA sequenziert oder als Metagenomics mittels einer Shotgun PCR, auch Shotgun Metagenomics genannt, mit $10^{7}$ Sequenzen repliziert. Ausgewertet wird zum einen die Diversität der Probe mit dem Nachweis von seltenen bzw. überbordenen Mengen (auch Fülle; engl. Abundance) von spezifischen Mikroben, bzw. die Struktur im Vergleich, als auch die Matrix der nachgewiesenen Mikroorganismen.

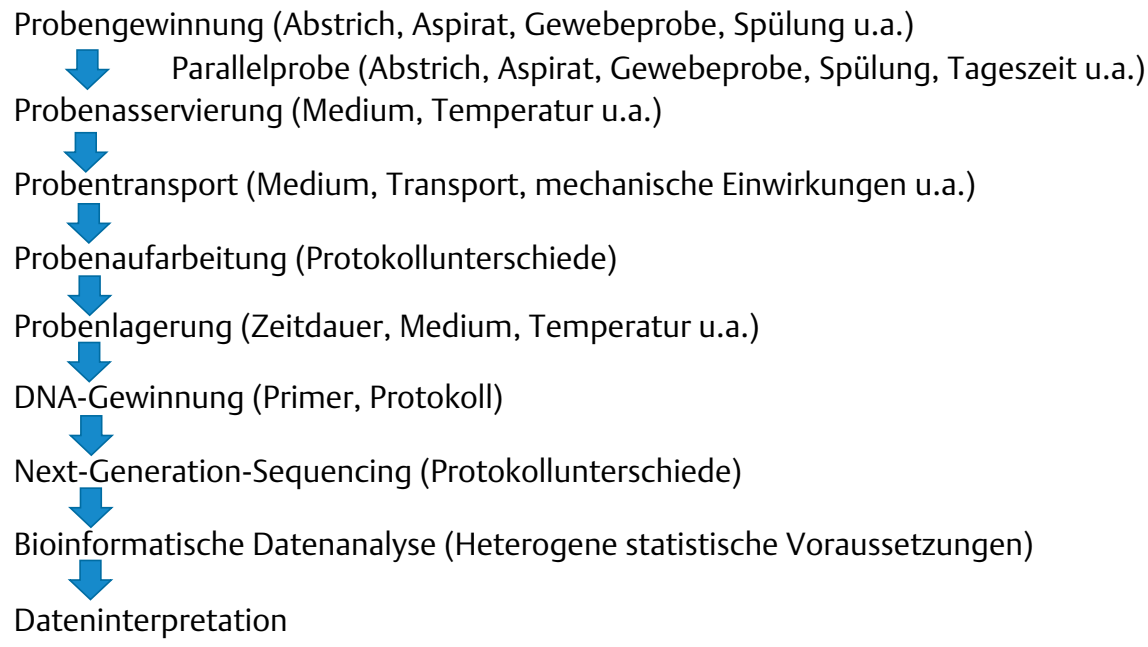

-Abb. 4 Ablaufschritte einer Mikrobiom-Studie mit möglichen Einflussfaktoren (modifiziert nach [7]). 
Die Sequenzierungsmethoden mit breiter Anwendung (Kettenabbruchsynthese nach Sanger, Pyrosequenzierung, Sequenzierung durch Synthese) unterscheiden sich im Hinblick auf technische Merkmale wie maximale Länge der Sequenz, Anzahl an Sequenzen sowie der Zeit pro Durchlauf und Durchsatzmenge. Dabei kommt der konventionellen Sequenzierung mittels Kettenabbruchsynthese nach Sanger, die relativ zeitaufwendig ist und die Analyse kleinerer DNA-Moleküle ermöglicht, die Rolle der Konfirmationstechnik zu. Heute werden Methoden der zweiten Generation zur zeiteffektiveren Analyse eingesetzt, da diese um ein Vielfaches schneller sequenzieren. Im Rahmen der für diese Arbeit referenzierten Arbeiten benutzte die Mehrheit die Technik der Pyrosequenzierung.

\subsection{Entnahmetechniken und technische Aspekte}

Zur Probengewinnung wurden und werden z.T. auch parallel verschiedene Verfahren genutzt. So basieren publizierte Daten auf Abstrichen, Gewebeproben, Aspirate, Spülungen usw. Als Goldstandard in der Probenentnahme und Post-Prozessierung galten zunächst die 2013 vom Humanen Mikrobiom Projekt publizierten Protokolle. Mittlerweile sind die Protokolle jeweils regional weiterentwickelt worden und ebenso die biostatistischen und bioinformatischen Auswertungen, sodass die Vergleichbarkeit der im Folgenden präsentierten Ergebnisse leider eingeschränkt ist und Widersprüche weiterhin auch methodisch hinterfragt werden müssen. Die Komplexität der gegenseitigen Beeinflussungen von Mikrobiom und Wirt, aber auch der Einzelnen am Mikrobiom beteiligten Mikroorganismen, erschwert die Forschung wesentlich. Durch die verbesserte Verfügbarkeit der Techniken des Next-Generation-Sequencing, auch aufbauend auf den Forschungen an Proteomics and Genomics, ermöglicht erfreulicherweise mehr und mehr Forschergruppen, auch Parameter des Mikrobiomes zu erheben. Die Auswertung ist aber derart komplex, dass im Einzelnen die Ergebnisse auf die Diversität des Mikrobiomes reduziert werden. Hier besteht auf dem Gebiet der Bioinformatik ein deutlicher Weiterentwicklungsbedarf, um die mühsam im Zusammenspiel Patient/Arzt/Mikrobiologe gewonnenen Daten insbesondere frei von falsch-negativen Veränderungen zu berichten.

Die in - Abb. 4 aufgeführten, technischen Schritte zur Bestimmung des Mikrobioms besitzen sämtlich Auswirkungen auf das Ergebnis.

So kann mit jedem Teilschritt Menge und Qualität der extrahierten DNA verändert werden. Eine Kontamination ist aufgrund der Sensitivität der nachgeschalteten Verfahren ein besonders wichtiges Problem. Untersuchungen zur technischen Bedeutung verschiedener Einflussfaktoren liefern aber widersprüchliche Ergebnisse: So veränderte eine Lagerung bei Raumtemperatur das Mikrobiom des Stuhles deutlich [8], in einer andern nicht wesentlich [9], während verschieden lange Lagerung der Proben mit $-80^{\circ}$ deutlich geringere Effekte auf die Diversität zeigte $[10,11]$. Andererseits erscheint das Mikrobiom der Vagina deutlich stabiler [12]. HNO-spezifische Studien sind rar: Für das laryngeale Mikrobiom konnte eine Vergleichbarkeit für Abstrich- und Biopsiebasierte Studien im Tiermodell des Schweines nachgewiesen werden [13]. Gleiches konnte für Patienten mit chronischer Rhinosinusitis (CRS) nachgewiesen werden mit 36 nachgewiesenen bakteriellen Spezies im Gewebe und 30.6 Spezies im Abstrich [14].

Um diesen diversen Einflussgrößen gerecht zu werden, gab es bereits mehrere Impulse, das Vorgehen bei Mikrobiom-Studien zu standardisieren. So sind online unter http://www.microbiome-standards.org/\#SOPS durch internationale Experten bereitgestellte SOPs (standard operational procedures) verfügbar. Diese SOPs geben u.a. für die Probenentnahme (z. B. von Speichel oder Wangenabstrich), die Sequenzierung und die Datenanalyse wertvolle Hinweise zu einem standardisierten Vorgehen. Dieses Problem wurde bereits in verschiedenen Journalen aufgegriffen [15], auch im Rahmen der internen Leitlinie zur Publikation von Mikrobiom-Daten [16]. Es gibt verschiedene Software-Pakete, die die komplexe Datenstruktur (geringe Anzahl von detektierten Bakterien bei hoher Anzahl verschiedener Spezies, hohe Homologie der untersuchten Bakterien mit 97\% Übereinstimmung bei gleichen Phyli) für Mikrobiom-Daten biostatistisch auswerten können wie QIIME [17-21], MOTHUR [22, 23], RDP Tools [24-27], und VAMPS [28]. Anhand der Übereinstimmung mit den gewählten Primern werden Operational Taxonomic Units (OTUs) identifiziert. Bei Vergleich von 16s RNA Genamplifizierung dem herkömmlichen Goldstandard - und MALDI-TOF (Matrix Assisted Laser Ionization Mass Spectrometry-Time of Flight) wurde der Untersuchung eines Mikrobiomes auf Streptococcus viridans mittels MALDI-TOF eine Sensitivität von $80 \%$ und eine Spezifität von $100 \%$ bescheinigt. Die Autoren empfahlen daher, parallel verschiedene Nachweisverfahren anzuwenden, was andererseits den Vorteil der Zeiteffizienz der Sequenzierungsmethoden der zweiten Generation wieder beseitigen würde [29]. Andererseits hilft MALDI-TOF bei Versagen einer konventionellen 16s RNA Sequenzierungstechnik, grampositive Bakterien (hier speziell Corynebakterien), zu identifizieren [30]. So stieg die Nachweisrate auf 92,49\% mittels MALDI-TOF MS im Vergleich zu 85,89\% durch konventionelle mikrobiologische Untersuchungstechniken [31].

Eine vergleichende Untersuchung der gleichen Proben auf drei verschiedenen industriellen Sequenzierungs-Plattformen konnte hier weitere relevante Abweichungen in der Datenanalyse nachweisen [32]. Während die Profile der Zusammensetzung des Mikrobiomes vergleichbar waren, erschien die durchschnittliche Fülle der Spezies in Abhängigkeit der Plattform, der verwendeten Datenbank und der Bioinformatikanalyse durchaus abweichend. Insbesondere die hohe Anzahl falsch-positiver Detektionen wurde bei detaillierter Betrachtung der bioinformatischen Analyse kritisiert [33]. Auch die Referenz-Bibliothek besitzt dabei einen, wenn im Vergleich zu den oben vorgestellten Parametern auch nachgeordneten, Einfluss auf das automatisiert präsentierten Endergebnis [34].

Insgesamt gilt die Vergleichbarkeit von Mikrobiom-Daten derzeit allgemein als stark eingeschränkt, was insbesondere auch die im Folgenden dargestellten Daten betrifft [35]. Vor diesem Hintergrund müssen die Bemühungen, die Originalartikel auch unter methodischen Gesichtspunkten standardisiert zu berichten, vorbehaltlos unterstützt werden.

\subsection{Allgemeine Einflussfaktoren}

Geschlecht, Alter, geografischer Lage und Klima, Kultur und Lebensweise sind in der Literatur diskutierte allgemeine Einflussfaktoren auf die Diversität des Mikrobiomes. Aber es wurde auch eine unterschiedliche prozentuale Verteilung der verschiedenen Bakterien zu verschiedenen Tageszeiten [36] berichtet. Mikrobiomenassoziationen werden alternativ durch Wirtfaktoren, wie Rauchen, Alkoholkonsum, Diät, Übergewicht, physikalische Inaktivität und Polymorphismen in wichtigen humanen Onkogenen erklärt. Auf einige Fak- 
toren mit Bedeutung für die Interpretation auch des „normalen“ Mikrobiomes soll im Folgenden eingegangen werden.

\subsubsection{Alter}

Im Rahmen des Wachstums vom jugendlichen zum erwachsenen Tier scheint auch das nasale Mikrobiom zu reifen. So konnte im Tiermodell des Schweines beim Vergleich von Neugeborenen zu 2-3 Wochen alten Tieren nachgewiesen werden, dass die Alpha- Diversität zunahm und charakteristische Taxa sich erst im Verlauf nachweisen ließen [37].

Im Tiermodell der Maus konnte beim Vergleich junger, mittel-alter und alter Mäuse signifikante Änderungen des Mikrobiomes, auch nach Kontakt mit Streptococcus pneumoniae (zugefügt durch lokale Spülung des oberen Respirationstraktes) demonstriert werden. So waren residente Staphylokokken and Haemophilus empfindlich gegenüber Streptococcus. Ferner nahm die Kolonisierung mit Streptococcus pneumoniae im Alter zu und die mukoziliäre Clearance erscheint weniger effektiv [38].

Für die chronische Rhinosinusitis (CRS) wurde eine altersbedingte Abnahme von S100 Proteinen als ursächlich für eine Veränderung des Mikrobioms mit Ausbildung einer CRS im Alter angesehen [39]. Dies mag einen Ansatz für einen gesonderten Endotyp der CRS im Alter bieten.

Auch im Oropharynx lassen sich Alterseffekte nachweisen: So ist das Mikrobiom beim alten Menschen charakterisiert durch eine vermehrte Fülle von Streptococci, speziell Streptococcus salivarius, aber nicht von Streptococcus pneumoniae [40].

Das Mikrobiom des Magens wies bei Hundertjährigen im Vergleich zu jüngeren, geschlechtsgleichen Personen eine andere Zusammensetzung auf mit konsekutiv erhöhten Plasmaleveln von IL-6 und -8. Generell nimmt die Biodiversität mit den Jahren ab mit einem Trend zur Zunahme fakultativ pathogener Bakterien. Bakterien, die aufgrund ihrer Produktion von kurzkettigen Fettsäuren wie Butyraten von Bedeutung für den Stoffwechsel der Enterozyten des Darmes sind, nehmen dagegen eher ab [41].

Alterseffekte wurden zwischenzeitlich auch durch eine Intervention am Mikrobiom zum therapeutischen Ziel: So wurde eine Tryptophan-reduzierte Diät an der Maus eingesetzt, um über eine Steigerung der Diversität des Mikrobiomes eine vorzeitige Alterung des Tieres zu verzögern [42]. Die positive Wirkung der Tryptophan-Diät soll dabei über eine Beeinflussung der B-Zell-Differenzierung vermittelt werden. Im Mikrobiom wurde eine stärkere Häufung von Akkermansia erreicht, einer Spezies, die häufig bei gesunden Personen nachgewiesen wird und die in besonderem Maß negativ von Alterungsprozessen des Wirtes betroffen ist [43].

\subsubsection{Gender}

Daten zu Geschlecht-spezifischen Unterschieden im Bereich des Mikrobioms werden derzeit noch als wenig verlässlich angesehen, obwohl durch Rollenzugehörigkeit bekannte Geschlechtsspezifische Unterschiede in der Ernährung für den Bereich des Gastrointestinaltraktes in einigen Studien nachweisbar waren. So wurden Bacteroides, Ruminococci, Eubacteria und Blautiae häufiger bei Männer und Treponemen häufiger bei Frauen nachgewiesen [44, 45]. Es wurde vermutet, dass die beobachteten Genderunterschiede Folge des Lebensstiles und auch der Ernährung sind.

\subsubsection{Rauchen}

Zigarettenrauch soll die Durchlässigkeit der Epithelbarriere gegenüber Mikroorganismen erhöhen und so zur Infektanfälligkeit beitragen. Als Ursache wird unter anderem ein dysbiotisches Mikrobiom angesehen, das z. B. die Karzinogenes im Bereich von Larynx und Lunge auslöst.

Untersuchungen zum Effekt des Rauchens zeigen unabhängig von der gewählten Technik, dass der Rauch exemplarisch die Zusammensetzung der oralen Bakterien verändert $[46,47]$, besonders der günstigen aeroben Spezies [48]. Außerdem können Bakterien das Karzinogen Nitrosamin aktivieren $[49,50]$. Außerdem macht Rauchen die Mundhöhle empfänglicher gegenüber einer Proliferation pathologischer bakterieller Spezies [51]. Entsprechend war die Alpha-Diversität des subgingivalen Mikrobiomes bei Rauchern signifikant reduziert. Ferner zeigte eine Analyse der Beta-Diversität auch Unterschiede von Rauchern gegenüber Patienten mit einer chronischen Periodontitis anderer Genese [52]. Ähnliche Veränderungen, die allerdings z.T. nur einseitig nachweisbar waren, zeigten sich auch im Nasopharynx [47] und dem Speichel [47]. Effekte auf das nasale Mikrobiom konnten demgegenüber nicht nachgewiesen werden [53].

Die Analyse der Ausatemluft [54] zeigte drei wesentliche Veränderungen: So wurden vermehrt pro-inflammatorische Marker als Hinweis auf vermehrte freie Sauerstoffradikale nachgewiesen. Diese zeigen eine Veränderung des endogenen Stoffwechsels. Zum zweiten wurden exogene Bestandteile nachgewiesen [55]. Schließlich zeigen sich auch hier Hinweise auf eine Interaktion von Mikrobiom und Wirt. Während 12 Metabolite zwischen aktiven Rauchern und absoluten Nichtrauchern unterscheiden helfen konnten, wiesen nur die Metabolite Eucalyptol und Benzylalcohol auch Unterschiede zwischen aktiven und früheren Rauchern in der Atemluft nach [54].

Für Gewebeproben der Lunge konnten zwei Taxa mit überproportional ausgeprägter relative Fülle, nämlich Variovorax und Streptococcus, nachgewiesen werden [56]. Spezifisch für das Auftreten von Plattenepithelkarzinomen konnte Acidovorax vermehrt nachgewiesen werden im Vergleich zu Kontrollgewebe.

Auch Passivrauchen verändert das Mikrobiom [57]: Das Mikrobiom des Nasenrachens und Oropharynx von Kindern unterscheidet sich in Abhängigkeit des Rauchverhaltens der Mütter. So nimmt die Nachweisrate von Streptococcus pneumoniae bei Aktiv- wie Passivrauchen signifikant zu, während die von Haemophilus influenzae unverändert erscheint.

\subsection{Ernährung}

\subsubsection{Präbiotika}

Ein Prä- oder Probiotikum ist eine Zubereitung, die lebensfähige Mikroorganismen enthält. Auch wenn im allgemeinen Verständnis oftmals die orale, systemische Anwendung im Vordergrund steht - z. B. durch Einnahme von Joghurtkulturen mit dem Ziel, die Darmflora zu stärken - sind Präbiotika nicht auf diese Anwendungsform begrenzt, sondern können auch z. B. lokal im HNO-Bereich Anwendung finden bzw. für diesen von Bedeutung sein. So wird bspw. eine Verminderung respiratorischer Infekte durch Präbiotika diskutiert.

Naturgemäß am besten untersucht ist aber die Anwendung als Nahrungsergänzung. So kann über die Nahrung die Zusammensetzung des intestinalen Mikrobioms des Menschen binnen 24-48 h effektiv und reproduzierbar moduliert werden [58]. Dies bietet auch 
einen Ansatz zur Verwendung von Präbiotika [59], um z. B. die Immunabwehr zu stimulieren. Präbiotika umfassen unverwertbare Kohlenhydrate, zu denen Ballaststoffe, resistente Stärke und Nicht-Stärke-Polysaccharide gehören, die nicht enzymatisch verdaut werden. Diese Stoffe werden durch das kommensale Mikrobiom im Bereich des Colon/terminalen Ileums zu Propionat, Butyrat und Acetat fermentiert [59]. Präbiotika beeinflussen die Zusammensetzung und die Aktivität des intestinalen Mikrobioms und können so Wohlbefinden und Gesundheit des Wirts verbessern [60]. Die stärkste Evidenz für eine präbiotische Wirkung liegen für die Fruktane vom Inulintyp (Fruktooligosaccharide, Inulin und Oligofruktose) sowie für Galaktooligosaccharide vor [61]. Diese Präbiotika sollen das Wachstum von Laktobazillen oder Bifidobakterien fördern [62]. So konnte im Tiermodell eine Veränderung der Zusammensetzung des intestinalen Mikrobioms sowie eine Abnahme des Körpergewichts durch Fütterung von kurzkettigen Fettsäuren erreicht werden [63].

HNO-spezifisch wurde exemplarisch topisch durch Inokulation von Staph. epidermidis mit und ohne Staph. aureus in einem Mausmodell mit Sinusitis untersucht, ob man das nasale Mikrobiom günstig beeinflussen könne [64]. Nach dreitägiger Anwendung waren mehr Becherzellen unter alleiniger Inokulation mit Staph. aureus nachweisbar. Zusätzliche Inokulation mit Staph. epidermidis dämpfte diesen Effekt signifikant, während alleinige Inokulation mit Staph. epidermidis vergleichbare und geringere Nachweisraten zur Kontrolle erbrachte. Das Konzept basiert auf der Annahme, dass Staph. epidermidis die Biofilm-Bildung durch Staph. aureus z. B. über die inhibitorisch wirksame Serin-Protease ESP kompetitiv hemmen kann. So wurde auch gezeigt, dass Staph. aureus in humanen Carriern durch zusätzliche Inokulation mit Staph. epidermidis im Rahmen einer Pilotstudie verdrängt werden können [65]. Diese Pilotstudie weisen damit interessante technologische Ansätze z. B. auch zur MRSA-Sanierung durch Antibiotika auf.

Für den Oropharynx konnte gezeigt werden, dass eine frühere Exposition von Streptococcus salivarius in-vitro die Zell-Adhärenz von Pneumokokken verhindern kann [66]. Weitere präbiotische Therapieansätze sind im Folgenden im Kontext des jeweils zu beeinflussenden Mikrobiomes aufgeführt.

\subsubsection{Alkohol}

Missbrauch von Tabak und Alkohol sind bedeutende Risikofaktoren zur Ausbildung von Kopf-, Halskarzinomen [67] und es wird vermutet, dass Mikroben diese Risikofaktoren mediieren. So besitzt das häufig auf der oralen Mukosa nachweisbare Bakterien Neisseria eine Alkoholdehydrogenase, die Ethanol zu dem Karzinogen Acetaldehyd umwandelt [68]. Die entsprechenden Studien für den Bereich der bösartigen Erkrankungen der Mundhöhle basieren allerdings v. a. auf Gewebe-basierten Untersuchungen mit älterer Technologie [50]. Alkoholabhängigkeit scheint mit dezidierten Veränderungen des gastrointestinalen Mikrobioms assoziiert zu sein, die sich im Stuhl nachweisen lassen [69]. So nimmt die Fülle von Klebsiellen zu, während Coprococcus, Faecalibacterium prausnitzii und Clostridiales abnehmen. Ferner treten Veränderungen auf, die bei einer Leberzirrhose ebenfalls beobachtet werden können. Zu diesen gehört eine Abnahme von Acidaminococcus und eine Zunahme von verschiedenen Laktobazillen und Bifidobakterien.

\subsection{Antibiotikatherapie}

Naheliegend ist ein kurzfristiger Effekt einer Antibiotikatherapie auf das Mikrobiom. So konnte nach fünftägiger oraler Anwendung von Amoxicillin mit Clavulansäure eine signifikant verringerte totale Bakterienkonzentration nachgewiesen werden [70]. Dabei war insbesondere auch die Bifidobakterien-Konzentration im Stuhl reduziert. Während dieser Effekt zu diesem Zeitpunkt erwartbar war, zeigte eine Nachuntersuchung zwei Monate nach der Antibiotikatherapie eine persistierende Veränderung des Mikrobioms. So war bei den sonst gesunden Probanden die Fülle von Bifidobakterien weiterhin gesenkt, und zwar auf ca. 60 \% des Ausgangswertes. Eine ältere Untersuchung zeigt eine höhere Resilienz des gastrointestinalen Mikrobiomes gegenüber Amoxicillin allein [71], bestätigt aber Individuen mit mehr als 2 monatiger, deutlicher Veränderung nach Antibiotikatherapie.

Eine Behandlung mit Antibiotika im frühen Kindesalter ist assoziiert mit einem erhöhten Risiko, später an Asthma zu erkranken. So erhöht eine Antibiotikatherapie in den Lebensjahren 0-2 das Asthmarisiko im Alter von 7,5 Jahren deutlich (odds ratio 1,75; $95 \%$ Konfidenzintervall 1,40-2,17), wobei mehrfache Antibiotikatherapien dieses Risiko weiter erhöhten (z. B. vier oder mehr Therapien: odds ratio 2,82; $95 \%$ Konfidenzintervall 2,19-3,63). Vor dem Hintergrund, dass Kinder mit atopischen Erkrankungen derzeit ca. 1,9-mal so häufig Antibiotika verschrieben bekommen als Kinder ohne Atopie [72] sollte auch das Verschreibungsverhalten durch HNO-Ärzte in dieser Altersgruppe kritisch hinterfragt werden.

\subsection{Impfung}

Eine Impfung gegen Haemophilus influenzae veränderte das Mikrobiom des Nasenrachens nicht relevant. Dies scheint auf eine sehr gezielte Eliminierung des Zielstoffes hinzuweisen [73]. Die orale Anwendung von Lactobacillus casei 431 im Rahmen einer prospektiven, placebo-kontrollierten Studie [74] vor und parallel zur Impfung gegen Influenza zeigte keine Änderung der Ansprechrate durch Serumkonversion, während die Dauer respiratorischer Beschwerden bei Anwendung des Präbiotikums kürzer war (Durchschnitt \pm Standardabweichung: 6,4 $\pm 6,1$ vs. 7,3 $\pm 9,7 d, P=0,0059)$. Da insgesamt Auswirkungen von Impfungen auf das Mikrobiom deutlich weniger häufig untersucht wurden, können hier aber methodische Schwächen nicht gänzlich ausgeschlossen werden.

\section{Mikrobiom in der HNO-Heilkunde}

\subsection{Ohr}

Trotz der gemeinsamen Pathophysiologie von Adenoiden und einer chronischen Otitis media mit Paukenerguss unterscheiden sich die Mikrobiome deutlich: So wurden im Mittelohrerguss Alloiococcus otitidis (23\% durchschnittliche relative Fülle), Haemophilus (22\%), Moraxella (5\%), und Streptococcus (5\%) nachgewiesen, wobei der Nachweis von Alloiococcus und Haemophilus invers korrelierte und Haemophilus häufiger bei beidseitigen Paukenergüssen nachgewiesen werden konnte [75]. Als bakterielle Erreger wurden ferner Turicella und Pseudomonas zunehmend in der Altersgruppe älter als 24 Monate nachgewiesen [76]. Während Turicella und Actinobacteria seltener mit einer ausgeprägteren Schallleitungsschwerhörigkeit assoziiert waren, scheint Haemophilus deutlich häufiger für diese 
ursächlich zu sein [76]. Ähnliche Mikrobiome wurden dabei auch bei australischen Kindern, die von Aborigines abstammen, nachgewiesen [77]. Dagegen ließen sich deutliche Unterschiede zwischen dem Mikrobiom des Paukenergusses und dem der Tonsilla palatina nachweisen [78]. Nach anderen Untersuchungen dominieren dagegen Pseudomonaden das Mikrobiom des Mittelohres mit einer Nachweisrate von 82,7\% [78]. Genetische Unterschiede konnten als ein möglicher ursächlicher Einflussfaktor für verschieden ausgeprägte Mikrobiome des Mittelohres beschrieben werden [79].

\subsection{Nasenrachen}

Eine Hyperplasie der Rachenmandel ist einer der häufigsten Gründe, ein Kind dem HNO-Arzt vorzustellen. Die Besiedelung im Nasenrachen bei Kindern wurde oben teilweise schon aufgrund des pathophysiologischen Zusammenhanges mit der chronischen Otitis media mit Paukenerguss behandelt. Pseudomonaden, Streptococci, Fusobacteriae und Pasteurellaceae dominieren das Mikrobiom der Adenoide [78].

Adenoide sind häufig auch mit einer akuten Rhinosinusitis vergesellschaftet [80]. Entsprechend wurde die Adenotomie zu Therapie der chronischen Rhinosinusitis im Kindesalter zugelassen [80]. Eine mögliche Erklärung für die wechselseitige Beeinflussung von Adenoiden und Nasennebenhöhlen im Kindesalter ist der Nachweis von Biofilm auf der Oberfläche von Adenoiden [81, 82]. Eine prospektive observierende Untersuchung konnte bei Kindern zwischen dem 1. und 12. Lebensjahr eine hohe Assoziation zwischen den Mikrobiomen auf Adenoiden, in deren Zentrum sowie im mittleren Nasengang nachweisen. Dies signalisiert, dass bei unseren pädiatrischen Patienten rezidivierende Infekte der Nasennebenhöhlen und des $\mathrm{Na}$ senrachens sich auf bakteriologischer Basis durch die Wiederausbreitung von bestimmten Mikrobiomen erklären lassen. Darüber hinaus kann auf diesem Wege der klinische Erfolg der Adenotomie bei Patienten mit einer begleitenden akuten Rhinosinusitis erklärt werden [83]. Im Bereich der Adenoide werden dabei hauptsächlich Haemophilus, Staphylococcus und Streptococcus nachgewiesen [80].

Dagegen konnte in anderen Studien kein signifikanter Zusammenhang zwischen der Besiedelung der Oberfläche von Adenoiden und dem Nachweis von Mikroben im Kern von Adenoiden nachgewiesen werden [83, 84], so dass der Zusammenhang von oberflächlichem Mikrobiom und Mikrobiom des Adenoidgewebes noch nicht als gesichert gelten kann.

Frühere Frühgeborene besitzen eine stärker ausgeprägte Heterogenität des Mikrobioms im Nasenrachen gleichen Lebensalters. Dabei waren Proteobacteriae vermehrt und Firmicutes vermindert. Diese Veränderungen persistierten trotz Infektion mit einem Rhinovirus, was als Zeichen einer persistierenden Immunmodulation bei Entzündungen der Atemwege nach stattgehabter Frühgeburtlichkeit interpretiert wurde [85].

Das Mikrobiom des Nasenrachens bei Kindern mit Asthma im Alter von 6-18 Jahren wiesen Moraxella, Staphylococcus, Dolosigranulum, Corynebacterium, Prevotella, Streptococcus, Haemophilus, Fusobacterium und Neisseriaceae verantwortlich für $86 \%$ aller Mikrobiomnachweise auf. Es konnten in verschiedenen Jahreszeiten keine relevanten Unterschiede der Alpha- und Beta-Diversität nachgewiesen werden. Dagegen variierte der relative Anteil von Haemophilus, Moraxella, Staphylococcus und Corynebacterium sowohl zwi- schen Sommerzeit und Herbst, als auch zwischen den untersuchten Altersgruppen [86].

Schließlich verändert ein akuter, viraler Infekt mit humanem Rhinovirus oder respiratorischen Syncytial Virus das Profil des Mikrobioms des Nasenrachens bei Untersuchung von N=123 gesunden Kindern deutlich im Bereich der bakteriellen Zusammensetzung [87]. Damit muss insgesamt das Mikrobiom des Nasenrachens zusammenfassend als hochvariabel eingeschätzt werden.

Aufgrund der möglichen pathophysiologischen Verbindung zwischen akuten viralen Infekten der oberen Atemwege mit dem Nasenrachen als möglichem Reservoir und dem Risiko, ein Asthma bronchiale als Kind zu entwickeln [88], wurden weitere Untersuchungen zum Mikrobiom des Nasenrachens unternommen. Prospektiv konnte bei 234 Kindern initial eine Besiedelung mit Staphylococcus oder Corynebacterium vor stabiler Kolonisierung mit Alloiococcus oder Moraxella nachgewiesen werden. Virus-assoziierte Veränderungen konnten durch den transienten Nachweis von Streptococcus, Moraxella oder Haemophilus nachgewiesen werden. Eine frühe asymptomatische Kolonisierung mit Streptococcus zeigte sich als starker Prädiktor, später eine Asthma bronchiale zu entwickeln [89].

Bei Vorliegen einer in der Bevölkerung erworbenen Pneumonie von Kindern zeigten Untersuchungen in 95,13\% eine bakterielle und nur in 0,72 \% eine virale Genese anhand des Mikrobiomes. Dabei wurden Paramyxoviridae, Herpesviridae, Anelloviridae, und Polyomaviridae am häufigsten nachgewiesen [90]. Eine umfangreiche Untersuchung der Viren im Nasenrachen zeigte einen viralen Ursprung von ca. 1/7 aller Mikrobiomnachweise bei mehr als 700000 Mikrobiomdaten von 210 Patienten. Es wurden Paramyxoviridae, Picornaviridae und Orthomyxoviridae nachgewiesen und es gelang zudem auch der Nachweis eines neuen Rhinovirus C [91]. Diese Untersuchungen zu den viralen Bestandteilen des Mikrobiomes deuten auf einen großen und weitgehend unbekannten Anteil hin, der in engem Austausch zu den bakteriellen Mikroorganismen steht.

Zur therapeutischen Beeinflussung des Nasenrachens-Mikrobiomes liegt ebenfalls eine Untersuchung vor. Nach dieser waren Pneumokokken im Mikrobiom von etwa 25\% der untersuchten Erwachsenen nachweisbar. Eine intranasale Applikation von Pneumokokken führte bei Erwachsenen mit großer Diversität des Nasenrachens häufiger zu einer anschließenden Pneumokokken-Besiedelung [92]. Diese begünstigte wiederum eine erhöhte Diversität des Mikrobioms.

\subsection{Nase und Nasennebenhöhlen}

Das endonasale Mikrobiom zeigt eine hohe Variabilität [93]. Damit unterscheidet sich das nasale Mikrobiom deutlich von dem eher weniger diversifizierten Mikrobiom der unteren Atemwege. Dennoch sind Nachweise von signifikanten Kohortenunterschieden berichtet worden [93]. Dabei sind auch intraindividuell Unterschiede im Mikrobiom vom mittleren Nasengang, der mittleren Muschel und der unteren Muschel nachweisbar [93]. Aerobe Bakterien sind in der Nasenhaupthöhle deutlich häufiger nachweisbar mit fast $80 \%$ der Mikroorganismen als Anaerobe [94].

Bei allen Patienten, die sich als Kontrolle oder wegen einer CRS einer Operation unterzogen, konnten auch Pilze in der Nase per Abstrich nachgewiesen werden [95]. Die Alpha-Diversität der Pilze war in Kontrollen etwas niedriger als bei CRS $(8,18$ vs. 12,14). Nach einer Operation der Nasennebenhöhlen nahm die Alpha-Diversität ab, was 
insbesondere mit einer Abnahme des Nachweises von Fusarium und Neocosmospora verbunden war.

Zur Frage einer therapeutischen Veränderung des nasalen Mikrobiomes erfolgte eine doppelt-blinde Cross-Over Studie: Ein Gemisch aus Laktobazillen und Bifidobakterien wurde an gesunden Probanden einmalig angewendet, ohne dass Nebenwirkungen oder eine Veränderung der kommensalen Bakterien sowie ausgewählter Zytokine (u. a. IL-8, -15) nachgewiesen werden konnte [96].

\subsubsection{Allergische Rhinitis}

In Ergänzung der traditionellen Hypothese der Begünstigung einer allergischen Sensibilisierung durch Hygiene hat sich eine Mikrobiom/Mikroflora Hypothese etabliert [97]: Durch Störung des gastrointestinalen Mikrobioms werden Immunmechanismen zur Toleranzentwicklung gestört. Auf diesem Weg soll der Anstieg der Inzidenz allergischer Erkrankungen [98, 99] und Asthma bronchiale [100] erklärt werden. Dies beruht auf Untersuchungen, nach denen eine verringerte Diversität des gastrointestinalen Mikrobioms assoziiert ist mit einer erhöhten Prävalenz von allergischen Erkrankungen im Schulalter $[98,99]$.

Dabei ist der genaue Mechanismus derzeit unklar. Unterstützt wird die Hypothese auch durch den Nachweis einer pathophysiologischen Verbindung von Störungen des gastrointestinalen Mikrobiomes mit dem Auftreten von Asthma [101-103]. Eine Möglichkeit der Beeinflussung der lokalen und systemischen Entzündung des Respirationstraktes [104] besteht in der Bildung von kurzkettigen Fettsäuren, die durch Fermentierung von Fasern durch intestinale Bakterien gebildet werden $[105,106]$. Auf das erhöhte Risiko zur Ausbildung eines Asthma bronchiales nach Antibiotikatherapie im früheren Kindesalter wurde bereits hingewiesen.

\subsubsection{Mikrobiom und chronische Rhinosinusitis}

Das Mikrobiom von Patienten mit CRS variiert stark. Dabei zeigten sich signifikante Unterschiede in der Zusammensetzung von CRS ohne nasale Polypen (CRSsNP) und mit nasalen Polypen (CRSwNP) [93]. CRSsNP scheint durch ein Mikrobiom mit verringerter Diversifizierung sowie anaerober Anreicherung gekennzeichnet zu sein [93]. Vermehrt werden Streptococcus, Haemophilus, und Fusobacterium nachgewiesen. CRSwNP wurde dagegen durch vermehrte Anteile von Staphylococcus, Alloiococcus, und Corynebacterium charakterisiert. Dabei sind die in CRS nachgewiesenen Veränderungen auch signifikant unterschiedlich vom Mikrobiom von Patienten mit allergischer Rhinitis.

Im mittleren Nasengang ließen sich bei Patienten mit Rhinosinusitis v. a. Staphylococcus aureus, Staphylococcus epidermidis und Propionibacterium acnes nachweisen [107]. In der Kieferhöhle wurden ebenfalls mehrheitlich aerobe Bakterien (ca. 60\%) nachgewiesen. Am häufigsten zeigten sich hier Streptococci $(28,8 \%)$ und Prevotella (17,8\%). Streptococcus pneumoniae, Haemophilus influenzae, und Staphylococcus aureus wurden dagegen in weniger als $10 \%$ der Proben nachgewiesen [94]. Die Varianz erscheint zwischen den Patienten größer als in verschiedenen nasalen Regionen. Dabei spiegelt insbesondere der mittlere Nasengang das Mikrobiom der gesamten Nase und Nasennebenhöhlen (u. a. im Vergleich zu Nasenloch, Kieferhöhle, Stirnhöhle, Keilbeinhöhle) repräsentativ wider, überschätzt tendenziell aber die Häufigkeit von Corynebakterien [108].

\subsection{Mundraum}

Das subgingivale Mikrobiom chinesischer Zwillinge ist beispielhaft für die große Vielfalt charakterisiert durch 18 Phyli und 179 Genu [109]. Karies war mit einem größeren Anteil von Actinobacteria und dem verminderten Nachweis von Fusobacteriae verbunden. Bei Erwachsenen konnten häufiger Treponemen nachgewiesen werden, die allerdings auch typisch für eine adulte Periodontitis seien sollen. Ebenfalls als Marker einer Peridontitis wurden Spirochäten, Synergistetes, Firmicutes und Chloroflexi angegeben, während Actinobacteria, besonders Actinomyces, eher eine protektive Bedeutung zugeschrieben wurde [110]. Da sehr aktuelle Daten eher eine Verringerung der Alpha-Diversität als Anzeichen einer Peridontitis ansehen ohne auf spezifische Mikroorganismen abzuheben, scheint hier der wissenschaftliche Diskurs noch kontrovers [111]. Zwillingsuntersuchungen daraufhin ergaben dass der genetische Einfluss auf das orale Mikrobiom dem der Umwelt, speziell der Ernährung, nachgeordnet ist [109]. Ferner hat eine Schwangerschaft ebenfalls einen untergeordneten Einfluss auf die Zusammensetzung des subgingivalen Mikrobiomes zu besitzen [112]. Demgegenüber scheint eine genetische Disposition für Karies diese Erkrankung stärker zu begünstigen, als das Mikrobiom von Zahnplaques [113]. Dennoch wurden Streptococcus, Veillonella, Actinomyces, Granulicatella, Leptotrichia und Thiomonas [114], Streptococcus, Granulicatella und Actinomyces [115] bzw. Streptococcus und Veillonella (in Kindern jünger als 30 Monate) [116] häufiger bei gleichzeitiger Karies nachgewiesen. Günstig und eher ohne Kariesnachweis dagegen ist ein Mikrobiom, das Leptotrichia, Selenomonas, Fusobacterium, Capnocytophaga oder Porphyromonas enthielt [116].

\subsubsection{Mikrobiom des Speichels}

Speichel besitzt eine große Fülle an Mikroorganismen [117, 118]. Zu diesen zählt Streptococcus, Dialister und Veillonella [119]. Im Vergleich von Speichel verschiedener Lebensalter erscheint im Kindesalter die Alpha-Diversität höher, wohingegen im Erwachsenenalter die absolute Fülle bei gleichartiger Zusammensetzung der Taxa höher ist [120]. Das zentrale, gesunde Mikrobiom des Speichels umfasst die Taxa Streptococcus, Prevotella, Neisseria, Haemophilus, Porphyromonas, Gemella, Rothia, Granulicatella, Fusobacterium, Actinomyces, Veillonella und Aggregatibacter [120] bzw. Streptococcus, Prevotella, Haemophilus, Lactobacillus und Veillonella [121]. Niedrigere Anteile von Neisseria, Aggregatibacter (Proteobacteriae), Haemophilus (Firmicutes) und Leptotrichia (Fusobacteriae) waren bei Patienten mit Plattenepithelkarzinomen im Bereich der Mundhöhle oder des Oropharynx zu detektieren [121]. Höhere Nachweisraten von Neisserien, Aggregatibacter, Haemophilus oder Leptotrichia weisen dagegen auf eine mögliche Tumorentwicklung hin. Ein erhöhter Zuckergehalt enoral, z. B. bei Diabetes mellitus Typ II, verringert die absolute Fülle der Mikroorganismen im Speichel und verschiebt ihre relative Fülle bei Jugendlichen [122]. Speichel wurde daher auch als mögliches Diagnostikum zur Detektion von schlecht eingestelltem Diabetes mit konsekutiv erhöhtem Kariesrisiko vorgeschlagen [122]. Ein Zusammenhang zu Karies konnte nur in einigen Studien bestätigt werden [123], in anderen nicht [124]. Es scheint aber zumindest ein Zusammenhang zu schlechter Mundhygiene zu bestehen [125].

Technisch ist die zirkadiane Rhythmik u. a. der Immunglobulin-AProduktion im Speichel von Bedeutung. Hier zeigte sich das Aspirat 
der Probengewinnung mittels Abstrich überlegen [126]. Weiterhin unterliegen auch der Nachweis von verschiedenen Bakterien, wie Firmicutes inkl. Streptococcus und Gemella, und Bacteroidetes inkl. Prevotella [127], Schwankungen. Entsprechend sollten auch die Tageszeiten der Probenentnahme bei Publikation von Studien zum Mikrobiom des Speichels berichtet werden.

Von grundlegender Bedeutung aus technischer Sicht ist eine Untersuchung zur Re-Test-Reliabilität der erhobenen Mikrobiom-Daten des Speichels [128]. So zeigte sich bei Probenentnahme alle 2 Monate über ein Jahr hinweg signifikant verschiedene absolute Häufigkeiten der nachgewiesenen Taxa sogar auf Ebene der Phyli und interindividuelle Unterschiede in der Zusammensetzung des Mikrobiomes mit signifikant verschiedener Alpha-Diversität. Ebenso schwankte der pH-Wert des Speichels im Jahresverlauf [128]. Diese Daten relativieren deutlich die Interpretationen von Unterschieden im Mikrobiom (auch in anderen Regionen), wobei die Autoren selbst die beobachteten Effekte den Jahreszeiten zuordnen. Proben, die in kürzerem Zeitverlauf z. B. einer Woche entnommen werden, scheinen dagegen deutlich stabiler im Hinblick auf ihre Reliabilität zu sein [129]. Aufgrund eines stärkeren Einflusses der jeweiligen Umgebung des Individuums als der Gene [130] wurde ferner vorgeschlagen, diesen Fakt bei der Rekrutierung der Kontrollgruppen zu berücksichtigen.

Mehr als 70\% der DNA im Speichel kann Bakterien zugeordnet werden, nur weniger als $1 \%$ stammt von Viren [131]. Das Mikrobiom des Speichels wird zunehmend auch im Rahmen systemischer Erkrankungen untersucht, z. B. um autoimmune Erkrankungen leichter diagnostizieren zu können [132] oder zur Krebsfrüherkennung [133]. So scheint bei M. Behcet das Mikrobiom weniger divers zu sein mit großer Fülle von Haemophilus parainfluenzae, aber deutlicher Abnahme von Alloprevotella rava und dem Genu Leptotrichia [134].

Bei Einnahme von Amoxicillin für 5 Tage nahm die relative Fülle von Veillonellaceae, Actinomycetaceae, Neisseriaceae, Prevotellaceae und Porphyromonadaceae zu, während Streptococcaceae und Gemellaceae abnahmen. Einnahme von Azithromycin dagegen verursachte eine Zunahme von Bifidobacteriales und Veillonellaceae, während Clostridiales, Neisseriaceae und Erysipelotrichaceae reduziert nachgewiesen wurden [119].

Zur Stimulation der Immunabwehr ist möglicherweise die Einnahme von Lactobacillus kunkeei YB38 nützlich, da dieses im Mausmodell die Immunglobulin-A-Sekretion im Speichel erhöht [135]. Dagegen konnte eine orale Einnahme von Lactobacillus paracasei F19 durch Kinder im Alter von 4-13 Monaten die Häufigkeit von Karies nicht beeinflussen [136]. Die regelmäßige Einnahme kommerziell erhältlicher Probiotika verringerte den Nachweis von Pilzen, speziell Candida albicans, deutlich [137], wobei ein Beleg für die klinische Relevanz noch aussteht. Gleichzeitig scheint die Alpha-Diversität des Mikrobioms des Speichels unter Einnahme von Probiotika eher zuzunehmen [138]. Als weitere Form der interventionellen Studie wurde der Einfluss von Xyilitol oder Sorbitol-haltigem Kaugummi auf das Mikrobiom untersucht. Kinder sollten 5 Wochen lang ca. 6g/die in Form von Kaugummis zu sich nehmen. Während Xylitol mittels Kultur nachweisbare Streptokokken reduzierte, nahm unter Sorbitol Veillonella atypica im Mikrobiom des Speichels signifikant ab [139].

\subsection{Rachenraum}

Streptokokken dominieren das Mikrobiom der gesunden Tonsille mit einer relativen Fülle von knapp 70\% [78]. Im Rachen ist diese Domi- nanz mit ca. 50\% nicht ganz so stark ausgeprägt, es folgen Fusobacteriae (ca. $8 \%$ ) und Prevotellae (ca. 7\%) mit deutlichem Abstand [140-142]. Im Bereich des Rachenringes liegt damit auf kleinstem Platz eine hohe Varianz bei Probenentnahme nur durch die Lokalisation bedingt (z. B. Rachenhinterwand versus Tonsilla palatina) vor [143].

Eine Tonsillenhyperplasie bei Kindern legt den Nachweis von Streptococcus (21,5\%), Neisseria (13,5\%), Prevotella (12,0\%), Haemophilus (10,2\%), Porphyromonas (9,0\%), Gemella (8,6\%), und Fusobacteriae $(6,4 \%)$ nahe $[144,145]$. Kinder mit PFAPA-Syndrom (periodischem Fieber, Stomatitis aphthosa, Pharyngitis und Adenitis) weisen in ihrer Tonsilla palatina wiederum ein anderes Mikrobiom auf: Dieses ist durch vermehrten Nachweis und vermehrte relative Fülle von Cyanobakteria charakterisiert, die zu Lasten der relativen Fülle von Streptokokken geht [146].

Bei Vorliegen einer chronischen Tonsillitis gelingt der kulturelle Nachweis von Erregern nur in ca. $60 \%$ [147, 148]. Anaerobier sind bei ca. 40-60\% der Patienten an der Oberfläche und bei knapp 50\% im Kern der Tonsilla palatina nachweisbar $[143,147]$. Dabei kann am häufigsten Porphyromonas nachgewiesen werden. Bei Erwachsenen scheint eine chronische Tonsillitis v. a. mit dem Nachweis von Fusobacterium necrophorum, Streptococcus intermedius und Prevotella melaninogenica/histicola assoziiert zu sein [144, 145].

Als interventionelle Studie zum Einfluss von Gurgeln mit Benzethoniumchlorid bei Patienten mit Halitosis konnte keine Veränderung des Mikrobiomes der Tonsille zeigen [149].

\subsubsection{Exkurs: Mikrobiom und Immunsystem}

Grundlage der funktionellen Bedeutung des Mikrobioms in der Pathogenese verschiedener immunvermittelter Erkrankungen ist die Modulation sowohl der angeborenen als auch der adaptiven Immunität durch das Mikrobiom bzw. umgekehrt die Beeinflussbarkeit des Mikrobioms durch Immunzellen [150]. Dabei beeinflusst das Mikrobiom die Immunität besonders über Interleukin-18- und -22-vermittelte Signalwege [151, 152]. Zusätzlich können Mikrobiom und Bund T-Zellen sich gegenseitig beeinflussen und das Mikrobiom so Einfluss auch auf das adaptive Immunsystem ausüben [150].

Exemplarisch sei in diesem Zusammenhang angeführt, dass eine stärkere Korrelation bei Frauen zwischen der Durchführung einer Tonsillektomie und dem Auftreten einer Sarkoidose (odds ratio 3,30; $95 \%$ Konfidenzintervall 0,88-12,39), als bei Männern (odds ratio 1,26; $95 \%$ Konfidenzintervall 0,10-16,52) nachgewiesen werden [153]. Dies deutet damit ebenso wie Daten zur Effektivität von Chemotherapien bei verschiedenem Mikrobiom (siehe unten) auf einen möglichen Einfluss des Rachen-Mikrobiomes auf die Entwicklung einer Autoimmunerkrankung hin.

\subsection{Larynx}

Das Mikrobiom des Larynx unterscheidet sich signifikant von dem des Rachens [140]. In erster Linie werden konsistent Firmicutes, Proteobacteriae und Bacteroidetes berichtet [154]. Detailliertere Untersuchungen geben auch Häufigkeitsangaben an: Die nachgewiesenen Phyli umfassen hier Firmicutes (54\%), Fusobacteriae (17\%), Bacteroidetes (15\%), Proteobacteriae (11\%), und Actinobacteria (3\%). Die nachgewiesenen Geni umfassten Streptococcus (36\%), Fusobacterium (15\%), Prevotella (12\%), Neisseria (6\%), und Gemella (4\%) [140]. 
In einer anderen Untersuchung der gleichen Arbeitsgruppe zeigte sich eine breite Varianz der Taxa mit verschiedener Häufigkeit [155]. So konnten die Phyli Firmicutes (46,4\%), Bacteroidetes (18,7\%), Fusobacteriae (16,9\%), Proteobacteriae (13,0\%), und Actinobacteriae (2,4\%) nachgewiesen werden, was die früheren Ergebnisse bestätigte. Die Geni Streptococcus (41,7\%), Fusobacterium (17,0\%), Prevotella (13,2\%), Gemella (4,1\%), Helicobacter $(2,6 \%)$, und Haemophilus (2,3\%) zeigten hier eine ähnliche Dominanz. Dabei unterscheidet sich das Mikrobiom beim Vergleich der Lokalisation von Stimmbändern und Taschenfalten nicht signifikant [13]. Technisch waren die Ergebnisse von Biopsien und Abstrichen vergleichbar, sodass hier ein weniger invasivens technisches Vorgehen für Studien und Kontrollgewebe gerechtfertigt werden kann [13].

\subsection{Trachea}

Bei Neugeborenen lässt sich Acinetobacter zuverlässig als Teil des Mikrobioms der Trachea nachweisen [156]. Damit erscheint die allgemein weit verbreitete Annahme, dass die Atemwege Neugeborener und speziell die Trachea steril seien, widerlegt. Eine verringerte Alpha-Diversität des trachealen Mikrobioms deutet dabei auf ein erhöhtes Risiko hin, an einer speziellen chronischen Lungenerkrankung, einer bronchopulmonalen Dysplasie, zu erkranken. Analog war die Diversität in beatmeten Patienten sowohl tracheal wie oral verringert. Dabei konnten die mittels Sequenzierung nachgewiesenen Taxa häufig nicht mittels Kultur nachgewiesen werden [157]. Beatmete Patienten mit Pneumonie besaßen eine bessere Prognose bei einer relativen Fülle $<4,6 \%$ von Pseudomonaden und $<70,8 \%$ von Staphylokokken [158]. Tracheotomierte Patienten zeigen bei Auftreten einer Infektion häufiger Haemophilus im Mikrobiom. Diese Zunahme erfolgt zu Lasten von Acinetobacter, Corynebacterium und Pseudomonas. Dabei nehmen im Rahmen des Infektes die Alpha- wie Beta-Diversität signifikant ab [159].

\section{8 Ösophagus}

\subsubsection{Gastro-ösophagealer Reflux}

Eine Untersuchung zeigte keinen Einfluss von Reflux auf das laryngeale Mikrobiom [160]. Bei Anwendung von Protonenpumpenhemmern bei Neugeborenen mit gastro-ösophagealem Reflux [161] veränderten sich weder Alpha- noch Beta-Diversität signifikant, aber Vertreter der Geni Lactobacillus und Stenotrophomonas nahmen ab zugunsten von Haemophilus. Nach Absetzen der Therapie nahm die Alpha- und Beta-Diversität dann zu mit Zunahme der relativen Fülle der Phyli Firmicutes, Bacteroidetes und Proteobacteriae. Damit spiegelte das Mikrobiom Alter und Diät wider.

\subsubsection{Neubildungen}

Plattenepithelkarzinome und Adenokarzinome sind die häufigsten malignen Neubildungen im Bereich der Speiseröhre. Die Ausbildung eines Adenokarzinoms scheint wesentlich durch einen gastro-ösophagealen Reflux begünstigt zu werden, der auch das komplexe Mikrobiom des Ösophagus beeinflusst und möglicherweise ein Ko-Faktor der Pathophysiologie des Barrett-Ösophagus darstellt[162]. Das relative Risiko an einem Adenokarzinom zu erkranken beträgt bei gastro-ösophagealem Reflux 30-400 [163].

Das normale Mikrobiom des Ösophagus erscheint von gram-positiven Bakterien (Phylus Firmicutes, v. a. mit dem Genus Streptococcus) geprägt [164]. Sowohl Reflux, wie auch bei Barett-Ösophagus veränderte sich dieses Bild zugunsten mehr gram-negativer Anaerobier der Phyli Bacteroidetes, Proteobacteriae, Fusobacteriae und Spirochäten. Ergänzend scheint die relative Häufigkeit von Taxa mehr als die absolute Menge von Bakterien wichtiger für die Pathophysiologie zu sein. So würden häufiger Veillonellae (19\%), Prevotellae (12\%), Neisseriae (4\%), und Fusobacteria (9\%) bei Vorliegen von Refluxerkrankung oder Barrett-Ösophagus nachgewiesen.

Um Auswirkungen des gastro-ösophagealen Refluxz. B. auch auf das Risiko an Tumoren des HNO-Fachgebietes zu erkranken besser untersuchen zu können, liegt mit der NordASCo Kohorte [165] Datenmaterial vor, das derzeit ausgewertet wird. Hier sind $945153 \mathrm{~Pa}$ tienten mit gastro-ösophagealem Reflux aus den skandinavischen Staaten erfasst, von denen sich 48433 (5,1\%) einem operativen Eingriff zur Refluxkontrolle unterzogen haben.

\section{Kopf-Hals-Tumoren und deren Behandlung}

\subsection{Karzinogenese}

Derzeit wird geschätzt, dass ca. 20\% aller Krebserkrankungen durch mikrobielle Erreger verursacht werden [166]. Im HNO-Fachgebiet anerkannt ist u. a. die Rolle des Humanen Papilloma Virus. Durch Verschiebungen innerhalb des Mikrobiomes kann eine Karzinogenese zusätzlich begünstigt werden, indem schützende Faktoren wie protektive mikrobielle Peptide wegfallen, Toxine sich sammeln oder pathogene Erreger sich vermehren können, um so z. B. über eine chronische Entzündung einer Karzinombildung zu begünstigen. Auch nach Bildung einer bösartigen Neubildung spielt das Mikrobiom eine Rolle: So kann es durch Mikroorganismen oder ihre Stoffwechselprodukte direkt onkogenetisch wirken, Tumorwachstum begünstigen, Wachstumsfaktoren bereitstellen und pro-inflammatorische und immunsuppressive Wirkung entfalten, die die körpereigenen Mechanismen zur Krebsbekämpfung schwächt.

Problematisch ist derzeit die Tumor-assoziierten, eher begleitenden Veränderungen von solchen mit kausalem Zusammenhang zu trennen. So wurde in Abhängigkeit des Antibiotika-Gebrauches ein erhöhtes Krebsrisiko nachgewiesen [167]. Demnach steigt das Risiko bei sechs oder mehr Verschreibungen von Antibiotika auf das relative Risiko eine bösartige Neubildung im Bereich von Mund und Rachen zu entwickeln von 1,38 (1,1,7-1,64; Alters- und Geschlechtsadaptiert) an. Im Bereich des Larynx war das Risiko einer Neubildung mit 1,45 $(1,08-1,94)$ sogar noch ausgeprägter.

Veränderungen des oralen Mikrobiomes sind stark assoziiert mit dem Auftreten von Tumoren des Mundraumes [168]. In einer MetaAnalyse von acht Studien zeigte sich ein erhöhtes Risiko, an einer bösartigen Neubildung im Kopf-Halsbereich zu erkranken bei Vorliegen einer Peridontitis von 2,63 (95\% Konfidenzintervall: 1,684,14 ) [169]. Da diese - wie oben beschrieben - mit deutlichen Veränderungen des oralen Mikrobiomes einhergeht, sind auch Unterschiede bei Vorliegen von Kopf-Hals-Tumoren zu erwarten:

Entsprechend zeigte eine Fall-Kontrollstudie unter Verwendung von Proben des Pharynx, Larynx und auch aus Metastasen von KopfHals-Tumoren in Tumoren eine verringerte Alpha-Diversität im Vergleich zu normaler Schleimhaut gleicher Lokalisation [170].

Die Beta-Diversität wies sowohl im Vergleich normaler Schleimhaut mit Lokalisation des Primärtumors, wie einer Metastase signi- 
fikante Unterschiede auf, aber auch zwischen Primärtumor und Metastase war die Beta Diversität deutlich verschieden. Im Vergleich zum physiologischen Mikrobiom der Mundhöhle wird das Tumormikrobiom durch eine vermehrte Häufigkeit von Bacteroidetes, Proteobacteriae, Spirochäten und Fusobacteriae bei Abnahme von Firmicutes und Actinobacteriae charakterisiert. Bei Primärtumoren des Larynx und Pharynx ließ sich eine vermehrte Besiedelung mit Fusobacteriae und Abnahme von Firmicutes nachweisen. In Metastasen schließlich nahmen ebenfalls Fusobacteriae zu und speziell der Anteil der Spezies Streptokokken aus dem Phylum der Firmicutes nahm ab. Zusätzlich war auch die Nachweisrate von Proteobakterien erhöht.

Auch das Risiko an einem Lymphom zu erkranken wird mit Mikrobiom-basierten Ansätzen erklärt. So weisen skandinavische Untersuchungen auf eine Seropositivität mit Borrelia burgdorferi hin $[171,172]$. MALT-Lymphome in verschiedenen, nicht gastrointestinalen Organen zeigten einen Nachweis von Chlamydophila psittaci $[173,174]$.

\subsection{Mikrobiome und Checkpoint-Inhibitoren}

Zur Behandlung von Kopf-Hals-Tumoren zugelassen bzw. in der Erprobung sind Antikörper, die PD1 (Programmed cell death protein 1, auch CD279) bzw. CTLA4 (cytotoxic T lymphocyte associated antigen 4) blockieren [175]. PD1- oder „Checkpoint-Inhibitoren“ wurden erst in den letzten Monaten auch für Deutschland zugelassen (wie Nivolumab). Weitere stehen hier vor der Zulassung und sind bereits durch die FDA zur Behandlung von Plattenepithelkarzinomen im Kopf- Hals-Bereich zugelassen (wie Pembrolizumab) [176]. PD-1 wird von aktivierten T-Lymphozyten, B-Zellen, Killer-Zellten (NKT) und $\mathrm{T}_{\text {reg }}$ Zellen exprimiert [177] und gehört zur Familie der CD 28 KoRezeptoren [178]. Dabei können die Liganden PD1- und PD-2 an diese Rezeptoren binden, wobei scheinbar nur PD-1 neben antigenpräsentierenden Zellen (z. B. Makrophagen [179]) auch von Tumorzellen exprimiert wird [180]. Ferner ist die Expression von PD-L1 in einigen Plattenepithelkarzinomen (Haut [181]) mit dem Tumorstadium assoziiert, während die Expression von PD-L2 eher von der Tumorgröße und dem Differentierungsgrad bestimmt wurde [181].

Das Ligandenpaar aus PD1- und PDL1 ist in der Tumorumgebung lokalisiert und soll helfen, dass die Tumorzellen der Immunreaktion des Wirtes entgehen $[182,183]$. Dabei bewirkt die Blockade dieser Verbindung einen deutlichen Anstieg von Interferon-Gamma (IFNGamma) [184] und damit eine signifikante Veränderung des Mikromilieus um den Tumor. Die Produktion von IFN-Gamma kann dabei deutlich durch das intestinale Mikrobiom beeinflusst werden [185]. Sowohl Ruminococcus (gram negativ), als auch Alistipes (gram-positiv) sind mit einer IFN-Gamma Produktion vergesellschaftet, während ein durch Anreicherung von Lactobacillus verändertes Mikrobiom diese Produktion nahezu verhindern kann. Untersuchungen im Tiermodell der Maus weisen darauf hin, dass das Mikrobiom die Effektivität einer Anti-PDL1 Therapie verstärken könnte. Hier zeigte ein Mikrobiom mit einem hohen Anteil von Bifidobacter ein verbessertes Ansprechen.

CTLA4 ist dagegen ein globaler Immunabwehrpunkt („Checkpoint“), um Immunantworten durch die Herunterregulation von CD4 ${ }^{+}$T effector $\left(T_{\text {eff }}\right)$ Zellen und Verstärkung von $T_{\text {reg }}$ Zellaktivität $[182,183]$ zu modulieren. Auch über diesen Mechanismus scheint das Mikrobiom Einfluss auf das Ansprechen von Krebstherapien Einfluss nehmen zu können. So weisen Mäuse, die ohne Bakterienbe- siedelung sind oder nach einer Antibiotikatherapie, nur einen geringen Effekt einer Anti-CTLA-4 Therapie [186]. Umgekehrt verändert die CTLA-4-Behandlung das Mikrobiom [186]. Schließlich kann eine immun ausgelöste Colitis unter CTA-4 Therapie mit Ipilimumab durch Bacteroides phlilym Anreicherung vermieden werden [187]. Weiterhin verbessert eine orale Therapie mit dem Antibiotikum Vancomycin eine CTLA4-Immuntherapie [186].

Im Tiermodell der Maus konnte bei genetisch identischem Tier mit Induktion eines Melanoms deutlich unterschiedliche Ansprechraten auf das unterschiedliche Mikrobiom von Tieren von zwei verschiedenen Züchtern erklärt und auf den günstigen Effekt von Bifidobakterien zurückgeführt werden. Die Zuführung von Bifidobakterien in den Tieren mit dem schlechteren Ansprechen konnte dabei die Tumorkontrolle und IFN-Gamma Produktion verbessern [188].

Insofern mag das Mikrobiom auch ein Biomarker für das Ansprechen einer Therapie bzw. ein Ansatzpunkt sein, um die Effektivität einer eingeleiteten Therapie günstig zu beeinflussen.

\subsection{Ausblick}

Die Behandlung des Mikrobiomes eröffnet ein völlig neues Therapiegebiet in Abhängigkeit des verwendeten Materiales. Die Stuhltransplantation zur Behandlung von Clostridium difficile wurde seitens des Bundesinstituts für Arzneimittel und Medizinprodukte (BfArM) als Behandlung mit einem Arzneimittel eingestuft, obwohl eine reproduzierbare Produktion des Stuhles gemäß herkömmlichen pharmakologischen Verständnis derzeit nicht möglich erscheint. Damit beginnt hier eine Grauzone, die auch im Hinblick auf präbiotische Therapien - auch für den Kopf-Hals-Bereich - kritisch zu betrachten ist. Die Diskussion um Veränderungen des Mikrobiomes auch durch eine „nur“ einmalige Antibiotikagabe hilft, das Verschreibungsverhalten unter diesem Aspekt kritisch zu hinterfragen. Bei gemäß aktueller Leitlinie 5-6-maliger Antibiotikatherapie vor Eingriff an den Gaumenmandeln sind hier in der Zukunft Datenerhebungen zur Abwägung der sekundären Schäden am Mikrobiom mit ihren Auswirkungen auf den Wirt sinnvoll und können ggf. eine frühere Intervention verifizieren helfen. Aufgrund der gegenseitigen Interaktionen von Wirt und Mikrobiom auch unabhängig einer Erkrankung und derzeitig noch begrenzten Kenntnisstand ist das Mikrobiom damit zu einer noch unplanbaren Größe zukünftiger Therapien geworden.

Interessenkonflikt

Der Autor gibt an, dass Honorare für Vortragstätigkeiten für die Firmen Pohl-Boskamp, Essex Pharma und Happersberger Otopront gezahlt wurden und er an der Durchführung von Drittmittel-Studien nach AMG für Allakos, Sanofi und GlaxoSmithKline beteiligt war bzw. ist.

Literatur

[1] Smith K, McCoy KD, Macpherson AJ. Use of axenic animals in studying the adaptation of mammals to their commensal intestinal microbiota. Semin Immunol 2007; 19: 59-69

[2] Sears CL, Pardoll DM. Perspective: alpha-bugs, their microbial partners, and the link to colon cancer. J Infect Dis 2011; 203: 306-311 
[3] Zhu L, Baker SS, Gill C et al. Characterization of gut microbiomes in nonalcoholic steatohepatitis (NASH) patients: a connection between endogenous alcohol and NASH. Hepatology 2013; 57: 601-609

[4] Zhu Q, Gao R, Wu W et al. The role of gut microbiota in the pathogenesis of colorectal cancer. Tumour Biol 2013; 34: 1285-1300

[5] Sheflin AM, Whitney AK, Weir TL. Cancer-promoting effects of microbial dysbiosis. Curr Oncol Rep 2014; 16: 406

[6] Boone DR, Castenholz RW, Garrity GM et al. Bergey's Manual ${ }^{\circledR}$ of Systematic Bacteriology. Springer; 2001

[7] Stallmach A, Vehreschild MJGT. Mikrobiom: Wissensstand und Perspektiven. Walter de Gruyter GmbH \& Co KG; 2016

[8] Roesch LF, Casella G, Simell O et al. Influence of fecal sample storage on bacterial community diversity. Open Microbiol J 2009; 3: 40-46

[9] Tal M, Verbrugghe A, Gomez DE et al. The effect of storage at ambient temperature on the feline fecal microbiota. BMC. Vet Res 2017; 13: 256

[10] Carroll IM, Ringel-Kulka T, Siddle JP et al. Characterization of the fecal microbiota using high-throughput sequencing reveals a stable microbial community during storage. PLoS One 2012; 7: e46953

[11] Kia E, Wagner Mackenzie B, Middleton D et al. Integrity of the Human Faecal Microbiota following Long-Term Sample Storage. PLoS One 2016; 11: e0163666

[12] Bai G, Gajer P, Nandy M et al. Comparison of storage conditions for human vaginal microbiome studies. PLoS One 2012; 7: e36934

[13] Hanshew AS, Jette ME, Tadayon S et al. A comparison of sampling methods for examining the laryngeal microbiome. PLoS One 2017; 12: e0174765

[14] Bassiouni A, Cleland EJ, Psaltis AJ et al. Sinonasal microbiome sampling: a comparison of techniques. PLoS One 2015; 10: e0123216

[15] Kumar R, Eipers P, Little RB et al. Getting started with microbiome analysis: sample acquisition to bioinformatics. Curr Protoc Hum Genet 2014; 82: 1818 11-18 1829

[16] Goodrich JK, Di Rienzi SC, Poole AC et al. Conducting a microbiome study. Cell 2014; 158: 250-262

[17] Navas-Molina JA, Peralta-Sanchez JM, Gonzalez A et al. Advancing our understanding of the human microbiome using QIIME. Methods Enzymol 2013; 531: 371-444

[18] Caporaso JG, Kuczynski ], Stombaugh J et al. QIIME allows analysis of high-throughput community sequencing data. Nat Methods 2010; 7 : 335-336

[19] Kuczynski J, Stombaugh J, Walters WA et al. Using QIIME to analyze 16S rRNA gene sequences from microbial communities. Curr Protoc Microbiol 2012; Chapter 1: Unit 1E 5

[20] Leray M, Knowlton N. Visualizing Patterns of Marine Eukaryotic Diversity from Metabarcoding Data Using QIIME. Methods Mol Biol 2016; 1452: 219-235

[21] Lawley B, Tannock GW. Analysis of 16S rRNA Gene Amplicon Sequences Using the QIIME Software Package. Methods Mol Biol 2017; 1537: 153-163

[22] Schloss PD, Westcott SL, Ryabin T et al. Introducing mothur: open-source, platform-independent, community-supported software for describing and comparing microbial communities. Appl Environ Microbiol 2009; 75: 7537-7541

[23] Yang S, Liebner S, Alawi M et al. Taxonomic database and cut-off value for processing mcrA gene 454 pyrosequencing data by MOTHUR. J Microbiol Methods 2014; 103: 3-5

[24] Maidak BL, Olsen G], Larsen N et al. The Ribosomal Database Project (RDP). Nucleic Acids Res 1996; 24: 82-85

[25] Maidak BL, Cole JR, Lilburn TG et al. The RDP-II (Ribosomal Database Project). Nucleic Acids Res 2001; 29: 173-174
[26] Cole JR, Chai B, Farris RJ et al. The Ribosomal Database Project (RDP-II): sequences and tools for high-throughput rRNA analysis. Nucleic Acids Res 2005; 33: D294-D296

[27] Bacci G, Bani A, Bazzicalupo M et al. Evaluation of the Performances of Ribosomal Database Project (RDP) Classifier for Taxonomic Assignment of 16S rRNA Metabarcoding Sequences Generated from Illumina-Solexa NGS. J Genomics 2015; 3: 36-39

[28] Huse SM, Mark Welch DB, Voorhis A et al. VAMPS: a website for visualization and analysis of microbial population structures. BMC Bioinformatics 2014; 15: 41

[29] Suzuk Yildiz S, Kaskatepe B, Altinok S et al. [Comparison of MALDI-TOF and $16 \mathrm{~S}$ rRNA methods in identification of viridans group streptococci]. Mikrobiyol Bul 2017; 51: 1-9

[30] Barberis C, Almuzara M, Join-Lambert O et al. Comparison of the Bruker MALDI-TOF mass spectrometry system and conventional phenotypic methods for identification of Gram-positive rods. PLoS One 2014; 9: e106303

[31] Funke G, von Graevenitz A, Clarridge JE 3rd et al. Clinical microbiology of coryneform bacteria. Clin Microbiol Rev 1997; 10: 125-159

[32] Allali I, Arnold JW, Roach J et al. A comparison of sequencing platforms and bioinformatics pipelines for compositional analysis of the gut microbiome. BMC Microbiol 2017; 17: 194

[33] Hawinkel S, Mattiello F, Bijnens L et al. A broken promise: microbiome differential abundance methods do not control the false discovery rate. Brief Bioinform 2017, doi:10.1093/bib/bbx104

[34] Lemos LN, Fulthorpe RR, Triplett EW et al. Rethinking microbial diversity analysis in the high throughput sequencing era. J Microbiol Methods 2011; 86: 42-51

[35] Stulberg E, Fravel D, Proctor LM et al. An assessment of US microbiome research. Nat Microbiol 2016; 1: 15015

[36] Spor A, Koren O, Ley R. Unravelling the effects of the environment and host genotype on the gut microbiome. Nat Rev Microbiol 2011; 9: $279-290$

[37] Slifierz M], Friendship RM, Weese JS. Longitudinal study of the early-life fecal and nasal microbiotas of the domestic pig. BMC Microbiol 2015; 15: 184

[38] Thevaranjan N, Whelan F], Puchta A et al. Streptococcus pneumoniae Colonization Disrupts the Microbial Community within the Upper Respiratory Tract of Aging Mice. Infect Immun 2016; 84: 906-916

[39] Renteria AE, Mfuna Endam L, Desrosiers M. Do Aging Factors Influence the Clinical Presentation and Management of Chronic Rhinosinusitis? Otolaryngol Head Neck Surg 2017; 156: 598-605

[40] Whelan F], Verschoor CP, Stearns JC et al. The loss of topography in the microbial communities of the upper respiratory tract in the elderly. Ann Am Thorac Soc 2014; 11: 513-521

[41] Biagi E, Nylund L, Candela $M$ et al. Through ageing, and beyond: gut microbiota and inflammatory status in seniors and centenarians. PLoS One 2010; 5: e10667

[42] van Beek AA, Hugenholtz F, Meijer B et al. Frontline Science: Tryptophan restriction arrests $B$ cell development and enhances microbial diversity in WT and prematurely aging Ercc1-/Delta7 mice. J Leukoc Biol 2017; 101: 811-821

[43] Schneeberger M, Everard A, Gomez-Valades AG et al. Akkermansia muciniphila inversely correlates with the onset of inflammation, altered adipose tissue metabolism and metabolic disorders during obesity in mice. Sci Rep 2015; 5: 16643

[44] Gomez A, Luckey D, Taneja V. The gut microbiome in autoimmunity: Sex matters. Clin Immunol 2015; 159: 154-162

[45] Mueller S, Saunier K, Hanisch C et al. Differences in fecal microbiota in different European study populations in relation to age, gender, and country: a cross-sectional study. Appl Environ Microbiol 2006; 72: $1027-1033$ 
[46] Wu J, Peters BA, Dominianni $C$ et al. Cigarette smoking and the oral microbiome in a large study of American adults. ISME J 2016; 10 : 2435-2446

[47] Charlson ES, Chen J, Custers-Allen R et al. Disordered microbial communities in the upper respiratory tract of cigarette smokers. PLoS One 2010; 5: e15216

[48] Lee J, Taneja V, Vassallo R. Cigarette smoking and inflammation: cellular and molecular mechanisms. J Dent Res 2012; 91: 142-149

[49] Verna L, Whysner J, Williams GM. N-nitrosodiethylamine mechanistic data and risk assessment: bioactivation, DNA-adduct formation, mutagenicity, and tumor initiation. Pharmacol Ther 1996; 71: 57-81

[50] Wang L, Ganly I. The oral microbiome and oral cancer. Clin Lab Med 2014; 34: 711-719

[51] Labriola A, Needleman I, Moles DR. Systematic review of the effect of smoking on nonsurgical periodontal therapy. Periodontol 2000 2005; 37: $124-137$

[52] Coretti L, Cuomo M, Florio E et al. Subgingival dysbiosis in smoker and nonsmoker patients with chronic periodontitis. Mol Med Rep 2017; 15: 2007-2014

[53] Yu G, Phillips S, Gail MH et al. The effect of cigarette smoking on the oral and nasal microbiota. Microbiome 2017; 5: 3

[54] Peralbo-Molina A, Calderon-Santiago M, Jurado-Gamez B et al. Exhaled breath condensate to discriminate individuals with different smoking habits by GC-TOF/MS. Sci Rep 2017; 7: 1421

[55] Filipiak W, Ruzsanyi V, Mochalski P et al. Dependence of exhaled breath composition on exogenous factors, smoking habits and exposure to air pollutants. J Breath Res 2012; 6: 036008

[56] Falana K, Knight R, Martin CR et al. Short Course in the Microbiome. ] Circ Biomark 2015; 4: 8

[57] Greenberg D, Givon-Lavi N, Broides A et al. The contribution of smoking and exposure to tobacco smoke to Streptococcus pneumoniae and Haemophilus influenzae carriage in children and their mothers. Clin Infect Dis 2006; 42: 897-903

[58] Turnbaugh PJ, Backhed F, Fulton L et al. Diet-induced obesity is linked to marked but reversible alterations in the mouse distal gut microbiome. Cell Host Microbe 2008; 3: 213-223

[59] Kaczmarek JL, Musaad SM, Holscher HD. Time of day and eating behaviors are associated with the composition and function of the human gastrointestinal microbiota. Am J Clin Nutr 2017; 106 : 1220-1231

[60] Gibson GR, Roberfroid MB. Dietary modulation of the human colonic microbiota: introducing the concept of prebiotics. J Nutr 1995; 125: $1401-1412$

[61] Staudacher HM, Whelan K. Altered gastrointestinal microbiota in irritable bowel syndrome and its modification by diet: probiotics, prebiotics and the low FODMAP diet. Proc Nutr Soc 2016; 75 : 306-318

[62] Walsh C], Guinane CM, O'Toole PW et al. Beneficial modulation of the gut microbiota. FEBS Lett 2014; 588: 4120-4130

[63] De Vadder F, Kovatcheva-Datchary P, Goncalves D et al. Microbiotagenerated metabolites promote metabolic benefits via gut-brain neural circuits. Cell 2014; 156: 84-96

[64] Cleland E], Drilling A, Bassiouni A et al. Probiotic manipulation of the chronic rhinosinusitis microbiome. Int Forum Allergy Rhinol 2014; 4: 309-314

[65] Iwase T, Uehara Y, Shinji H et al. Staphylococcus epidermidis Esp inhibits Staphylococcus aureus biofilm formation and nasal colonization. Nature 2010; 465: 346-349

[66] Manning J, Dunne EM, Wescombe PA et al. Investigation of Streptococcus salivarius-mediated inhibition of pneumococcal adherence to pharyngeal epithelial cells. BMC Microbiol 2016; 16: 225
[67] World Cancer Research Fund / American Institute for Cancer Research. Food, Nutrition, Physical Activity, and the Prevention of Cancer: a Global Perspective. Washington DC: AICR 2007. Nachlesbar unter http://www.aicr.org/assets/docs/pdf/reports/Second_Expert_ Report.pdf; ISBN: 978-0-9722522-2-5

[68] Muto M, Hitomi Y, Ohtsu A et al. Acetaldehyde production by non-pathogenic Neisseria in human oral microflora: implications for carcinogenesis in upper aerodigestive tract. Int J Cancer 2000; 88: 342-350

[69] Dubinkina VB, Tyakht AV, Odintsova VY et al. Links of gut microbiota composition with alcohol dependence syndrome and alcoholic liver disease. Microbiome 2017; 5: 141

[70] Mangin I, Leveque C, Magne F et al. Long-term changes in human colonic Bifidobacterium populations induced by a 5 -day oral amoxicillin-clavulanic acid treatment. PLoS One 2012; 7: e50257

[71] De La Cochetiere MF, Durand T, Lepage P et al. Resilience of the dominant human fecal microbiota upon short-course antibiotic challenge. J Clin Microbiol 2005; 43: 5588-5592

[72] Pols DH], Nielen MM], Bohnen AM et al. Atopic children and use of prescribed medication: A comprehensive study in general practice. PLoS One 2017; 12: e0182664

[73] Feazel LM, Santorico SA, Robertson CE et al. Effects of Vaccination with 10-Valent Pneumococcal Non-Typeable Haemophilus influenza Protein D Conjugate Vaccine (PHiD-CV) on the Nasopharyngeal Microbiome of Kenyan Toddlers. PLoS One 2015; 10: e0128064

[74] Jespersen L, Tarnow I, Eskesen D et al. Effect of Lactobacillus paracasei subsp. paracasei, L. casei 431 on immune response to influenza vaccination and upper respiratory tract infections in healthy adult volunteers: a randomized, double-blind, placebo-controlled, parallel-group study. Am J Clin Nutr 2015; 101: 1188-1196

[75] Chan CL, Wabnitz D, Bardy |] et al. The microbiome of otitis media with effusion. Laryngoscope 2016; 126: 2844-2851

[76] Krueger A, Val S, Perez-Losada M et al. Relationship of the Middle Ear Effusion Microbiome to Secretory Mucin Production in Pediatric Patients With Chronic Otitis Media. Pediatr Infect Dis | 2017; 36: 635-640

[77] Jervis-Bardy J, Rogers GB, Morris PS et al. The microbiome of otitis media with effusion in Indigenous Australian children. Int ] Pediatr Otorhinolaryngol 2015; 79: 1548-1555

[78] Liu CM, Cosetti MK, Aziz M et al. The otologic microbiome: a study of the bacterial microbiota in a pediatric patient with chronic serous otitis media using 16SrRNA gene-based pyrosequencing. Arch Otolaryngol Head Neck Surg 2011; 137: 664-668

[79] Santos-Cortez RL, Hutchinson DS, Ajami N] et al. Middle ear microbiome differences in indigenous Filipinos with chronic otitis media due to a duplication in the A2ML1 gene. Infect Dis Poverty 2016; 5: 97

[80] Fokkens W], Lund V], Mullol ] et al. European Position Paper on Rhinosinusitis and Nasal Polyps. 2012; Rhinol Suppl 2012; 23: 3 p preceding table of contents, 1-298

[81] Zuliani G, Carron M, Gurrola J.et al. Identification of adenoid biofilms in chronic rhinosinusitis. Int J Pediatr Otorhinolaryngol 2006; 70: 1613-1617

[82] Beule AG, Hosemann W. [Bacterial biofilms]. Laryngorhinootologie 2007; 86: 886-895 quiz 896-889

[83] Subtil ], Rodrigues JC, Reis L et al. Adenoid bacterial colonization in a paediatric population. Eur Arch Otorhinolaryngol 2017; 274: 1933-1938

[84] Taylan I, Ozcan I, Mumcuoglu I et al. Comparison of the surface and core bacteria in tonsillar and adenoid tissue with Beta-lactamase production. Indian J Otolaryngol Head Neck Surg 2011; 63: 223-228 
[85] Perez GF, Perez-Losada M, Isaza N et al. Nasopharyngeal microbiome in premature infants and stability during rhinovirus infection. J Investig Med 2017; 65: 984-990

[86] Perez-Losada M, Alamri L, Crandall KA et al. Nasopharyngeal Microbiome Diversity Changes over Time in Children with Asthma. PLoS One 2017; 12: e0170543

[87] Rosas-Salazar C, Shilts MH, Tovchigrechko A et al. Differences in the Nasopharyngeal Microbiome During Acute Respiratory Tract Infection With Human Rhinovirus and Respiratory Syncytial Virus in Infancy. J Infect Dis 2016; 214: 1924-1928

[88] Rosas-Salazar C, Shilts MH, Tovchigrechko A et al. Nasopharyngeal Microbiome in Respiratory Syncytial Virus Resembles Profile Associated with Increased Childhood Asthma Risk. Am J Respir Crit Care Med 2016; 193: 1180-1183

[89] Teo SM, Mok D, Pham K et al. The infant nasopharyngeal microbiome impacts severity of lower respiratory infection and risk of asthma development. Cell Host Microbe 2015; 17: 704-715

[90] Xu L, Zhu Y, Ren L et al. Characterization of the nasopharyngeal viral microbiome from children with community-acquired pneumonia but negative for Luminex xTAG respiratory viral panel assay detection. J Med Virol 2017, doi:10.1002/jmv.24895

[91] Lysholm F, Wetterbom A, Lindau C et al. Characterization of the viral microbiome in patients with severe lower respiratory tract infections, using metagenomic sequencing. PLoS One 2012; 7: e30875

[92] Cremers A], Zomer AL, Gritzfeld JF et al. The adult nasopharyngeal microbiome as a determinant of pneumococcal acquisition. Microbiome 2014; 2: 44

[93] Lal D, Keim P, Delisle J et al. Mapping and comparing bacterial microbiota in the sinonasal cavity of healthy, allergic rhinitis, and chronic rhinosinusitis subjects. Int Forum Allergy Rhinol 2017; 7: 561-569

[94] Ivanchenko OA, Karpishchenko SA, Kozlov RS et al. The microbiome of the maxillary sinus and middle nasal meatus in chronic rhinosinusitis. Rhinology 2016; 54: 68-74

[95] Cleland E], Bassiouni A, Boase $\mathrm{S}$ et al. The fungal microbiome in chronic rhinosinusitis: richness, diversity, postoperative changes and patient outcomes. Int Forum Allergy Rhinol 2014; 4: 259-265

[96] Martensson A, Greiff L, Lamei SS et al. Effects of a honeybee lactic acid bacterial microbiome on human nasal symptoms, commensals, and biomarkers. Int Forum Allergy Rhinol 2016; 6: 956-963

[97] Noverr MC, Huffnagle GB. The 'microflora hypothesis' of allergic diseases. Clin Exp Allergy 2005; 35: 1511-1520

[98] Bisgaard H, Li N, Bonnelykke K et al. Reduced diversity of the intestinal microbiota during infancy is associated with increased risk of allergic disease at school age. J Allergy Clin Immunol 2011; 128: 646-652 e641-645

[99] Sjogren YM, Jenmalm MC, Bottcher MF et al. Altered early infant gut microbiota in children developing allergy up to 5 years of age. Clin Exp Allergy 2009; 39: 518-526

[100] Abrahamsson TR, Jakobsson HE, Andersson AF et al. Low gut microbiota diversity in early infancy precedes asthma at school age. Clin Exp Allergy 2014; 44: 842-850

[101] Huang Y]. Asthma microbiome studies and the potential for new therapeutic strategies. Curr Allergy Asthma Rep 2013; 13: 453-461

[102] Hansel TT, Johnston SL, Openshaw PJ. Microbes and mucosal immune responses in asthma. Lancet 2013; 381: 861-873

[103] Suzaki H, Watanabe S, Pawankar R. Rhinosinusitis and asthma-microbiome and new perspectives. Curr Opin Allergy Clin Immunol 2013; 13: $45-49$

[104] Herbst T, Sichelstiel A, Schar C et al. Dysregulation of allergic airway inflammation in the absence of microbial colonization. Am J Respir Crit Care Med 2011; 184: 198-205
[105] Cait A, Hughes MR, Antignano F et al. Microbiome-driven allergic lung inflammation is ameliorated by short-chain fatty acids. Mucosal Immunol 2017, doi:10.1038/mi.2017.75

[106] Marsland BJ. Regulation of inflammatory responses by the commensal microbiota. Thorax 2012; 67: 93-94

[107] Ramakrishnan VR, Feazel LM, Gitomer SA et al. The microbiome of the middle meatus in healthy adults. PLoS One 2013; 8: e85507

[108] Ramakrishnan VR, Gitomer S, Kofonow JM et al. Investigation of sinonasal microbiome spatial organization in chronic rhinosinusitis. Int Forum Allergy Rhinol 2017; 7: 16-23

[109] Du Q, Li M, Zhou X et al. A comprehensive profiling of supragingival bacterial composition in Chinese twin children and their mothers. Antonie Van Leeuwenhoek 2017; 110: 615-627

[110] Abusleme L, Dupuy AK, Dutzan $\mathrm{N}$ et al. The subgingival microbiome in health and periodontitis and its relationship with community biomass and inflammation. ISME J 2013; 7: 1016-1025

[111] Ai D, Huang R, Wen J et al. Integrated metagenomic data analysis demonstrates that a loss of diversity in oral microbiota is associated with periodontitis. BMC Genomics 2017; 18: 1041

[112] Adriaens LM, Alessandri R, Sporri S et al. Does pregnancy have an impact on the subgingival microbiota? J Periodontol 2009; 80: 72-81

[113] Zhang M, Chen Y, Xie L et al. Pyrosequencing of Plaque Microflora In Twin Children with Discordant Caries Phenotypes. PLoS One 2015; 10: e0141310

[114] Ling Z, Kong J, Jia P et al. Analysis of oral microbiota in children with dental caries by PCR-DGGE and barcoded pyrosequencing. Microb Ecol 2010; 60: 677-690

[115] Jiang W, Zhang J, Chen H. Pyrosequencing analysis of oral microbiota in children with severe early childhood dental caries. Curr Microbiol 2013; 67: 537-542

[116] Xu H, Hao W, Zhou Q et al. Plaque bacterial microbiome diversity in children younger than 30 months with or without caries prior to eruption of second primary molars. PLoS One 2014; 9: e89269

[117] Ahn J, Yang L, Paster BJ et al. Oral microbiome profiles: 16S rRNA pyrosequencing and microarray assay comparison. PLoS One 2011; 6: e22788

[118] Hasan NA, Young BA, Minard-Smith AT.et al. Microbial community profiling of human saliva using shotgun metagenomic sequencing. PLoS One 2014; 9: e97699

[119] Abeles SR, Jones MB, Santiago-Rodriguez TM et al. Microbial diversity in individuals and their household contacts following typical antibiotic courses. Microbiome 2016; 4: 39

[120] Ling Z, Liu X, Wang Y et al. Pyrosequencing analysis of the salivary microbiota of healthy Chinese children and adults. Microb Ecol 2013; 65: 487-495

[121] Guerrero-Preston R, Godoy-Vitorino F, Jedlicka A et al. 16S rRNA amplicon sequencing identifies microbiota associated with oral cancer, human papilloma virus infection and surgical treatment. Oncotarget 2016; 7: 51320-51334

[122] Goodson JM, Hartman ML, Shi P et al. The salivary microbiome is altered in the presence of a high salivary glucose concentration. PLoS One 2017; 12: e0170437

[123] Zhou J, Jiang N, Wang Z et al. Influences of pH and Iron Concentration on the Salivary Microbiome in Individual Humans with and without Caries. Appl Environ Microbiol 2017; 83: e02412-e02416

[124] Foxman B, Luo T, Srinivasan U et al. The effects of family, dentition, and dental caries on the salivary microbiome. Ann Epidemiol 2016; 26: 348-354

[125] Mashima I, Theodorea CF, Thaweboon B et al. Exploring the salivary microbiome of children stratified by the oral hygiene index. PLoS One 2017; 12: e0185274 
[126] Hamuro K, Kotani Y, Toba M et al. Comparison of salivary IgA secretion rate collected by the aspiration method and swab method. Biosci Microbiota Food Health 2013; 32: 107-112

[127] Takayasu L, Suda W, Takanashi K et al. Circadian oscillations of microbial and functional composition in the human salivary microbiome. DNA Res 2017; 24: 261-270

[128] Cameron SJ, Huws SA, Hegarty MJ et al. The human salivary microbiome exhibits temporal stability in bacterial diversity. FEMS Microbiol Ecol 2015; 91: fiv091

[129] Belstrom D, Holmstrup P, Bardow A et al. Temporal Stability of the Salivary Microbiota in Oral Health. PLoS One 2016; 11: e0147472

[130] Shaw L, Ribeiro ALR, Levine AP et al. The Human Salivary Microbiome Is Shaped by Shared Environment Rather than Genetics: Evidence from a Large Family of Closely Related Individuals. MBio 2017; 8(5): e01237-17

[131] Lazarevic V, Whiteson K, Gaia N et al. Analysis of the salivary microbiome using culture-independent techniques. J Clin Bioinforma 2012; 2: 4; doi: 10.1186/2043-9113-2-4

[132] Abrao AL, Falcao DP, de Amorim RF et al. Salivary proteomics: A new adjuvant approach to the early diagnosis of familial juvenile systemic lupus erythematosus. Med Hypotheses 2016; 89: 97-100

[133] Wolf A, Moissl-Eichinger C, Perras A et al. The salivary microbiome as an indicator of carcinogenesis in patients with oropharyngeal squamous cell carcinoma: A pilot study. Sci Rep 2017; 7: 5867

[134] Coit P, Mumcu G, Ture-Ozdemir F et al. Sequencing of 16S rRNA reveals a distinct salivary microbiome signature in Behcet's disease. Clin Immunol 2016; 169: 28-35

[135] Asama T, Arima TH, Gomi T et al. Lactobacillus kunkeei YB38 from honeybee products enhances IgA production in healthy adults. J Appl Microbiol 2015; 119: 818-826

[136] Hasslof P, West CE, Videhult FK et al. Early intervention with probiotic Lactobacillus paracasei F19 has no long-term effect on caries experience. Caries Res 2013; 47: 559-565

[137] Dos Santos AL, Jorge AO, Dos Santos SS et al. Influence of probiotics on Candida presence and IgA anti-Candida in the oral cavity. Braz J Microbiol 2009; 40: 960-964

[138] Dassi E, Ballarini A, Covello G et al. Enhanced microbial diversity in the saliva microbiome induced by short-term probiotic intake revealed by $16 \mathrm{~S}$ rRNA sequencing on the lonTorrent PGM platform. J Biotechnol 2014; 190: 30-39

[139] Soderling E, ElSalhy M, Honkala E et al. Effects of short-term xylitol gum chewing on the oral microbiome. Clin Oral Investig 2015; 19: 237-244

[140] Gong HL, Shi Y, Zhou L et al. The Composition of Microbiome in Larynx and the Throat Biodiversity between Laryngeal Squamous Cell Carcinoma Patients and Control Population. PLoS One 2013; 8: e66476

[141] Gong H, Shi Y, Zhou X et al. Microbiota in the Throat and Risk Factors for Laryngeal Carcinoma. Appl Environ Microbiol 2014; 80: 7356-7363

[142] Gong H, Wang B, Shi Y et al. Composition and abundance of microbiota in the pharynx in patients with laryngeal carcinoma and vocal cord polyps. J Microbiol 2017; 55: 648-654

[143] Humphreys G], McBain AJ. Continuous culture of sessile human oropharyngeal microbiotas. J Med Microbiol 2013; 62: 906-916

[144] Jensen A, Fago-Olsen $\mathrm{H}$, Sorensen $\mathrm{CH}$ et al. Molecular mapping to species level of the tonsillar crypt microbiota associated with health and recurrent tonsillitis. PLoS One 2013; 8: e56418

[145] Watanabe H, Goto S, Mori $\mathrm{H}$ et al. Comprehensive microbiome analysis of tonsillar crypts in IgA nephropathy. Nephrol Dial Transplant 2016, doi:10.1093/ndt/gfw343
[146] Tejesvi MV, Uhari M, Tapiainen T et al. Tonsillar microbiota in children with PFAPA (periodic fever, aphthous stomatitis, pharyngitis, and adenitis) syndrome. Eur J Clin Microbiol Infect Dis 2016; 35: 963-970

[147] Khadilkar MN, Ankle NR. Anaerobic Bacteriological Microbiota in Surface and Core of Tonsils in Chronic Tonsillitis. J Clin Diagn Res 2016; 10: MC01-MC03

[148] Gul M, Okur E, Ciragil P et al. The comparison of tonsillar surface and core cultures in recurrent tonsillitis. Am J Otolaryngol 2007; 28: 173-176

[149] Iwamura Y, Hayashi J, Sato T et al. Assessment of oral malodor and tonsillar microbiota after gargling with benzethonium chloride. J Oral Sci 2016; 58: 83-91

[150] Honda K, Littman DR. The microbiota in adaptive immune homeostasis and disease. Nature 2016; 535: 75-84

[151] Thaiss CA, Zmora N, Levy M et al. The microbiome and innate immunity. Nature 2016; 535: 65-74

[152] Sonnenberg GF, Monticelli LA, Alenghat T et al. Innate lymphoid cells promote anatomical containment of lymphoid-resident commensal bacteria. Science 2012; 336: 1321-1325

[153] Sawahata M, Nakamura Y, Sugiyama Y. Appendectomy, tonsillectomy, and risk for sarcoidosis - A hospital-based case-control study in Japan. Respir Investig 2017; 55: 196-202

[154] Hanshew AS, Jette ME, Thibeault SL. Characterization and comparison of bacterial communities in benign vocal fold lesions. Microbiome 2014; 2: 43

[155] Gong H, Shi Y, Xiao X et al. Alterations of microbiota structure in the larynx relevant to laryngeal carcinoma. Sci Rep 2017; 7: 5507

[156] Lohmann P, Luna RA, Hollister EB et al. The airway microbiome of intubated premature infants: characteristics and changes that predict the development of bronchopulmonary dysplasia. Pediatr Res 2014; 76: 294-301

[157] Kelly B], Imai I, Bittinger $\mathrm{K}$ et al. Composition and dynamics of the respiratory tract microbiome in intubated patients. Microbiome 2016; 4: 7

[158] Hotterbeekx A, Xavier BB, Bielen K et al. The endotracheal tube microbiome associated with Pseudomonas aeruginosa or Staphylococcus epidermidis. Sci Rep 2016; 6: 36507

[159] Perez-Losada M, Graham R], Coquillette M et al. The temporal dynamics of the tracheal microbiome in tracheostomised patients with and without lower respiratory infections. PLoS One 2017; 12 : e0182520

[160] Jette ME, Dill-McFarland KA, Hanshew AS et al. The human laryngeal microbiome: effects of cigarette smoke and reflux. Sci Rep 2016; 6: 35882

[161] Castellani C, Singer G, Kashofer K.et al. The Influence of Proton Pump Inhibitors on the Fecal Microbiome of Infants with Gastroesophageal Reflux-A Prospective Longitudinal Interventional Study. Front Cell Infect Microbiol 2017; 7: 444

[162] Yang L, Chaudhary N, Baghdadi J et al. Microbiome in reflux disorders and esophageal adenocarcinoma. Cancer J 2014; 20: 207-210

[163] Lagergren J, Bergstrom R, Lindgren A et al. Symptomatic gastroesophageal reflux as a risk factor for esophageal adenocarcinoma. $N$ Engl J Med 1999; 340: 825-831

[164] Yang H, Gu J, Wang KK et al. MicroRNA expression signatures in Barrett's esophagus and esophageal adenocarcinoma. Clin Cancer Res 2009; 15: 5744-5752

[165] Maret-Ouda J, Wahlin K, Artama M et al. Cohort profile: the Nordic Antireflux Surgery Cohort (NordASCo). BMJ Open 2017; 7: e016505

[166] Pevsner-Fischer M, Tuganbaev T, Meijer M et al. Role of the microbiome in non-gastrointestinal cancers. World J Clin Oncol 2016; 7: $200-213$ 
[167] Kilkkinen A, Rissanen H, Klaukka T et al. Antibiotic use predicts an increased risk of cancer. Int J Cancer 2008; 123: 2152-2155

[168] Schmidt BL, Kuczynski J, Bhattacharya A et al. Changes in abundance of oral microbiota associated with oral cancer. PLoS One 2014; 9: e98741

[169] Zeng XT, Deng AP, Li C et al. Periodontal disease and risk of head and neck cancer: a meta-analysis of observational studies. PLoS One 2013; 8: e79017

[170] Shin JM, Luo T, Kamarajan P et al. Microbial Communities Associated with Primary and Metastatic Head and Neck Squamous Cell Carcinoma - A High Fusobacterial and Low Streptococcal Signature. Sci Rep 2017; 7: 9934

[171] Schollkopf C, Melbye M, Munksgaard L et al. Borrelia infection and risk of non-Hodgkin lymphoma. Blood 2008; 111: 5524-5529

[172] Chang CM, Landgren O, Koshiol J et al. Borrelia and subsequent risk of solid tumors and hematologic malignancies in Sweden. Int J Cancer 2012; 131: 2208-2209

[173] Aigelsreiter A, Leitner E, Deutsch AJ et al. Chlamydia psittaci in MALT lymphomas of ocular adnexals: the Austrian experience. Leuk Res 2008; 32: 1292-1294

[174] Aigelsreiter A, Gerlza T, Deutsch AJ et al. Chlamydia psittaci Infection in nongastrointestinal extranodal MALT lymphomas and their precursor lesions. Am J Clin Pathol 2011; 135: 70-75

[175] Topalian SL, Taube JM, Anders RA et al. Mechanism-driven biomarkers to guide immune checkpoint blockade in cancer therapy. Nat Rev Cancer 2016; 16: 275-287

[176] Lipson EJ, Forde PM, Hammers HJ et al. Antagonists of PD-1 and PD-L1 in Cancer Treatment. Semin Oncol 2015; 42: 587-600

[177] Okazaki T, Chikuma S, Iwai Y et al. A rheostat for immune responses: the unique properties of PD-1 and their advantages for clinical application. Nat Immunol 2013; 14: 1212-1218
[178] Lazar-Molnar E, Yan Q, Cao E et al. Crystal structure of the complex between programmed death-1 (PD-1) and its ligand PD-L2. Proc Natl Acad Sci U S A 2008; 105: 10483-10488

[179] Xu J, Sun HH, Fletcher CD et al. Expression of Programmed Cell Death 1 Ligands (PD-L1 and PD-L2) in Histiocytic and Dendritic Cell Disorders. Am J Surg Pathol 2016; 40: 443-453

[180] Yamazaki T, Akiba H, Iwai $\mathrm{H}$ et al. Expression of programmed death 1 ligands by murine T cells and APC. J Immunol 2002; 169: 5538-5545

[181] Jiao Q, Liu C, Li W et al. Programmed death-1 ligands 1 and 2 expression in cutaneous squamous cell carcinoma and their relationship with tumour-infiltrating dendritic cells. Clin Exp Immunol 2017; 188: 420-429

[182] Pardoll DM. The blockade of immune checkpoints in cancer immunotherapy. Nat Rev Cancer 2012; 12: 252-264

[183] Pardoll D. Cancer and the Immune System: Basic Concepts and Targets for Intervention. Semin Oncol 2015; 42: 523-538

[184] Zang X, Allison JP. The B7 family and cancer therapy: costimulation and coinhibition. Clin Cancer Res 2007; 13: 5271-5279

[185] lida N, Dzutsev A, Stewart CA et al. Commensal bacteria control cancer response to therapy by modulating the tumor microenvironment. Science 2013; 342: 967-970

[186] Vetizou M, Pitt JM, Daillere R et al. Anticancer immunotherapy by CTLA-4 blockade relies on the gut microbiota. Science 2015; 350: 1079-1084

[187] Dubin K, Callahan MK, Ren B et al. Intestinal microbiome analyses identify melanoma patients at risk for checkpoint-blockade-induced colitis. Nat Commun 2016; 7: 10391

[188] Sivan A, Corrales L, Hubert $\mathrm{N}$ et al. Commensal Bifidobacterium promotes antitumor immunity and facilitates anti-PD-L1 efficacy. Science 2015; 350: 1084-1089 